\title{
اتجاهات جديدة في الترجمة: رموز "الإيموجي" والترجمة
}

$$
\text { د. فايز بن علي الشهري }
$$

كلية اللغات والترجمة- جامعة الملك سعود 
أصبحت التقنيةُ لغةً العصر وبشكلٍ لا يمهل الوقت اللحاق بها، ويزداد الأمرُ صعوبةً على اللغات التي ليست مدعومة بلغة البرامج والأنظمة التقتية الحديثة، أو لا تتعامل معها بنفس وتيرتها. لقد قلبت وسائل الاتصال الحديثة والمواقع الإلكترونية موازين استخدام اللغات. كما أن مراسلات البريد الإلكتروني ووسائل التواصل الاجتماعي والمدونات والمواقع الإكترونية قد فرضت لغة مكتوبة جديدة وتعابير مستحدثة، واستخدام الرسوم والصور والرموز والإثارات كطريقةٍ للتعبير عن المشاعر والعواطف بدلًا من الكلمات. اليوم وفي ظل الثورة التكنولوجية الهائلة، صارت الكتابة اليومية في وسائل التواصل الاجتماعي بطرق تختصر عاملي الزمان والمكان، وعليه ابتكرت وسيلة للتواصل سريعة مثل رموز الإيموجي. كيف أثرت التقنية إيجابًا أو سلبًا في تطور الترجمة كما هو الحال على سبيل المثال في التغير 》الإيموجيه في وسائل التواصل الاجتماعي للتواصل دون معرفة مسبقة بلغة الآخر ، إلخ.. ؟ نسعى في هذه الدراسة للإجابة على التساؤل السابق وغيره. كلمات مفتاحية: لغة الإيموجي، الترجمة، وسائل التواصل الاجتماعي، اللغة والتقنية، التواصل، الانفرادية.

\section{Résumé :}

La technologie est devenue la langue de l'époque à tel point que le temps, lui-même, n'arrive pas à la rattraper. La difficulté s'accroît pour les langues qui en sont dépourvues. Les réseaux sociaux et les sites internet ont bouleversé l'usage des langues. C'est ainsi que les messages électroniques, les réseaux sociaux et les sites ont imposé une nouvelle langue d'écriture, de nouvelles expressions et un certain emploi de dessins, d'images, de symboles et de signes comme une façon d'exprimer utilisée à la place des mots. Aujourd'hui et à l'ombre de l'énorme révolution technologique, l'écriture quotidienne utilisée sur les réseaux sociaux est devenue abréviative. Sur ce, un nouveau moyen de communication "Emoji" a été créé. La question qui se pose donc et à laquelle notre étude répondra est :

Comment la technologie a négativement ou positivement influencé sur l'évolution de la traduction; comme c'est le cas de l'"Emoji" employé, sur les réseaux sociaux, pour communiquer avec l'Aure? 
مع تطور حياة الإنسان وتكوين المجتمعات البشرية، بدأ ذلك الإنسان الأول بالتعبير عما يريده لنقل أفكاره وتداولها عن طريق الوسائل المتاحة له في ذلك الوقت، وكان من وسائل تواصله التعبير عن طريق الرموز. وعليه فقد مرت الكتابةُ وأدوات التواصل بين تلك الك الجماعات بعدة مراحل تطورية حتى وصلت إلى شكاها المتداول في لغات العالم الحالية (Joseph Piercy:2013). والمتتبع لنثأة المجتمع وتطوره خلال التاريخ الإنساني، يلحظ محطات غيّرت وجهة التاريخ.

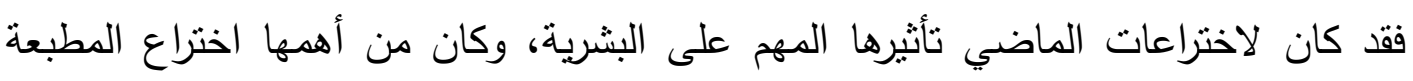

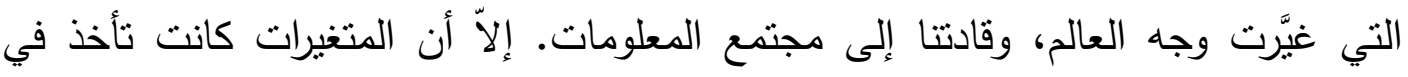

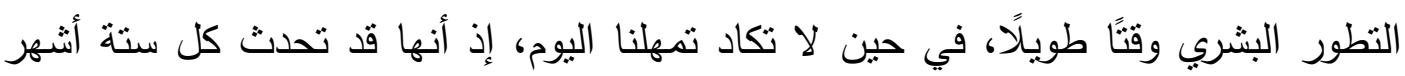
وربما في المستقبل القريب أقل من هذه المدة. وقد غيرت الاختراعات -من خلال التقنيات

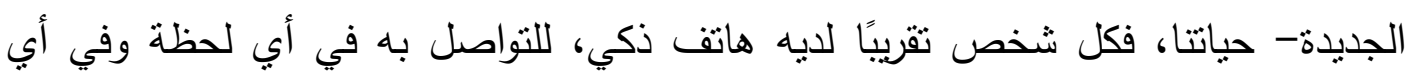

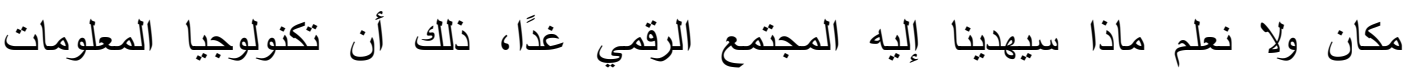

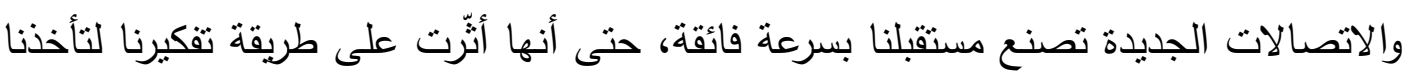

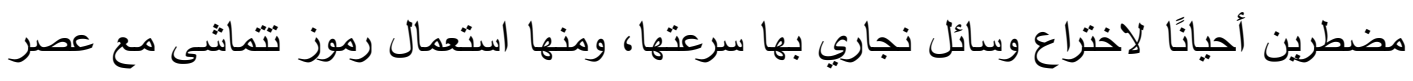

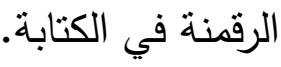

2.1. الرموز التعبيرية "الإيموجي": لم تعد الكلمات الوسيلة الوحيدة للتعبير خصوصًا عن

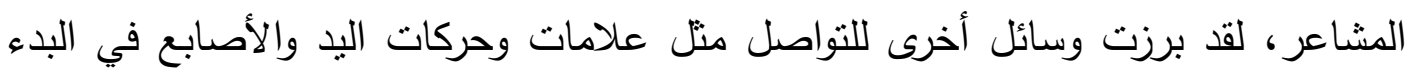
كلغة الإنتارة للى ذوي الاحتياجات الخاصة، ومع نطور التنتية واستخدامها في النواصل،

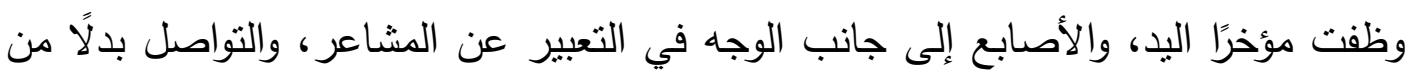

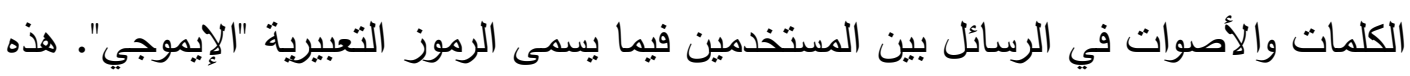

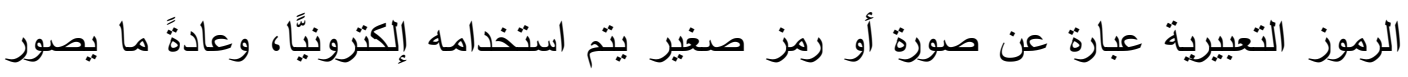


المشاعر أو الأشياء الثائعة. وبالتالي، يمكن أن يكون الرمز التعبيري أي شيء ، من تعبيرات الوجه إلى المواد الغذائية ، والرياضية والأعلام الوطنية، إلخ..، وتعبير الوجه من هذه

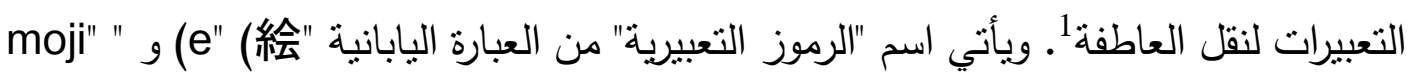
emojis (文字 بسرعة منذ عام 2010 ، وشاع استخدامها في الرسائل النصية والوسائط الاجتماعية وفي التطبيقات مثل Instagram و what's up Snapchat. لقد استبدلت الرموز التعبيرية إلى حد كبير باعتبارها الطريقة القياسية للتعبير عن المشاعر في رسالة أو تعليق. ولقد شهد العقدان الماضيان تغيرات سريعة في المعلومات، بدءًا من مفهوم العولمة، مرورًا بوسائل التواصل الاجنماعي، وصولًا إلى حقبة مستقبل الانفرادية. 3.1. ما هو عصر الانفرادية؟ مصطلح التقرد Singularity: يصف ظاهرة التطور العلمي المنسارع والتي ستوصّل في النهاية إلى نتائج لا يمكن التنبؤ بها، واستخدمت بشكل علمي على يد عالم الفيزياء والرباضيات ستانيسلو أولام Stanislaw Ulam عام 1958، وعبارة (التقرد التكنولوجي (Technological Singularity ظهرت على يد كاتب الخيال العلمي فيرنور فينغ Vernor Vinge وقد عثنا خلال العقدين الأخيرين تغيرات وتطورات معلوماتية كبيرة ومتسارعة؛ ويؤكد كثير من العلماء، أنه يحدث كل ج أنثهر تغييرٌ كبير فيها، وفي المستقبل كما يقول المفكر وصاحب فكرة الإنفرادية: "بها أن كمبة التخزين تتضاعف كل 7 أشهر تقريبًا، فإنه بحول عام

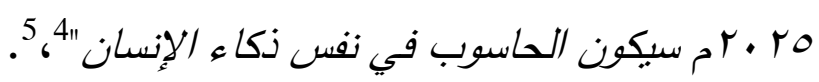

\footnotetext{
${ }^{1}$ https://writingexplained.org/emoji-vs-emoticon-difference

2 https://techterms.com/definition/emoii

3 http://www.fikrmag.com/article details.php?article id=211

${ }^{4}$ http://www.fikrmag.com/article details.php?article id=211

${ }^{5}$ https://electronics.howstuffworks.com/gadgets/high-tech-gadgets/technologicalsingularity.htm
} 
وقد يصل الأمر أبعد من ذلك، ستكون الآلات أو الحواسيب يومًا ما أذكى من الإنسان، وسيكون هناك اندماج ما بين الآلات والإنسان، وهكذا ينسحب الأمر على مهنة الترجمة (فايز الثهري، 1435هـ). يقول مؤلف كتاب الإنفرادية كورزويل . Ray Kurzweil. "هنالك احتمال كبير، وفي فترة زمنية قادمة 0ح • rم لن يكون هناك تمبيزّ بين الآلات والبشر، وكل جانب في حياتك سيتأثر بهذه الآلات " (Kofi Annan:2005). مما أدى إلى إنشاء بنك SoftBank للاتصالات وللشرائح 4.1. التواصل والتقتية: إن التطور التقني المستمر الذي يعيشه العالم حاليًا وظهور وسائل الاتصال الحديثة والمواقع الإكترونية قد أنتجت وسائل اتصال وأثرت في استخدام اللغات، حتى ذهبت للتواصل أبعد من ذلك باستخدام رموز وتعابير موحدة ومفهومة بكلٍ اللغات (الإيموجي) متجاوزين مفهوم حدود اللغة الطبيعية. ووفقًا لما سبق هذه بعض التساؤلات: هل يعود إنسان العالم الرقمي اليوم بوسائل تواصله إلى ما كان عليه جده الأول؟ أم أن العالم يسير نحو تكوين وسيلة تواصل عبر لغة ذات رموز موحدة؟ وما مدى تأثير هذا النوع من التواصل على الترجمة؟ وهل بالصورة ضمن مفهوم الإنفرادية يتفاعل مع الآلة والعكس صحيح؟ يتبادل البشر يوميا 6 مليار تعبير إيموجيه، فيا ترى كم يتبادل البشر الآن؟ هذه بعض الأسئلة التي نسعى في هذه الدراسة للإجابة عليها والتي تتاولها بعض الباحثين من أنحاء العالم في سياقات تقترب أو تبتعد منها (أنظر

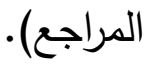

${ }^{6}{ }^{6}$ https://en.wikipedia.org/wiki/The Singularity is Near

${ }^{8} \mathrm{http} / / /$ www.lefigaro.fr/langue-francaise/actu-des-mots/2017/07/17/37002-

20170717ARTFIG00037-pierre-halte-l-emoji-n-est-pas-un-appauvrissement-du-langage.php 
اعتمدت الدراسة على المنهج الوصفي التحليلي، وقد نّّ تصميم اسنبانة تحتوي على عبارات حول استخدام الرموز التعبيرية وتوظيفها في الترجمة خصوصًا عبر وسائل التواصل الاجتماعي.

1.2 حدود الاراسة: استهدفت الدراسة فئة أعضاء هيئة التدريس والطلبة وشملت عينة من 249 كان أغلبهم من جامعة الملك سعود، يمنل الطلبة 84\% والبقية من أعضاء هيئة تدريس (16\%)، وتتراوح أعمارهم ما بين 18 -60، منهم 204 ذكور (81.9\%)، 45 إناث (18.1\%)، (أنظر الرسم 1).

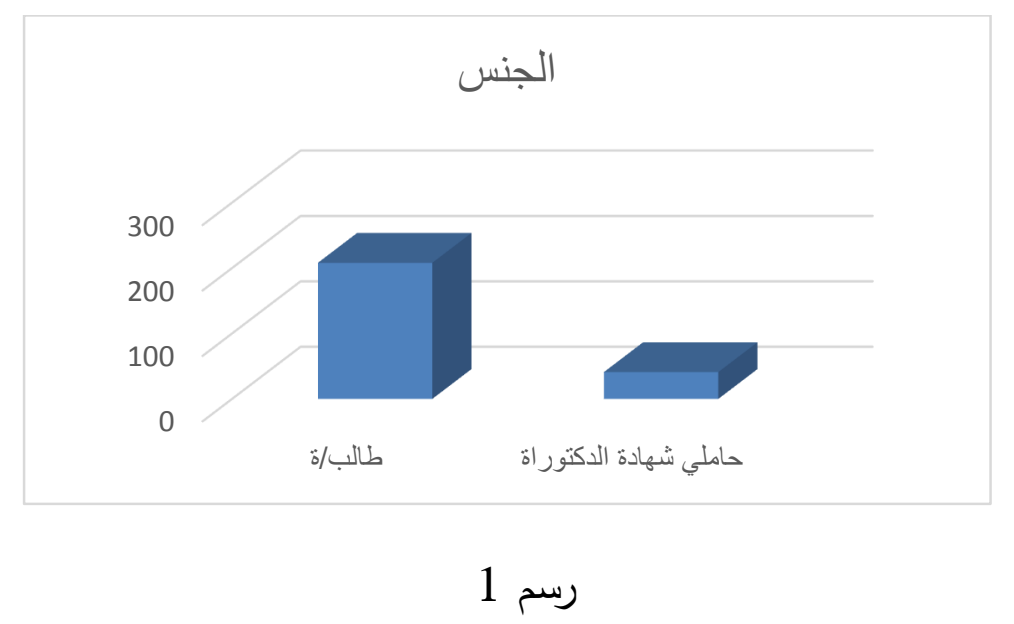

طبقت في الفترة من منتصف يناير حتى نهاية فبراير 2019. 2.2 الاستبانة: في البداية قمنا بحساب معامل ألفا لحساب درجة الثقة بالاسنبانة والاعتماد عليها في النتائج فكانت درجة التقة هي 82\% وهي درجة جيدة للاعتماد عليها، أنظر

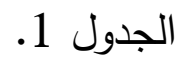

Reliability Statistics

\begin{tabular}{|c|c|c|}
\hline Cronbach's Alpha & Cronbach's Alpha Based on Standardized Items & N of Items \\
\hline 0.819 & 0.822 & 19 \\
\hline & $1 \mathrm{~J}$ جدو
\end{tabular}


وزع 300 استبانة على قسمين يدوي وإلكتروني 9: ومن الورقي استبعد بعض الاستبانات لعدم الإجابة على بعض العبارات، ولم يعد بعضها. لقد احتوت الاستبانة على ثلاث أقسام: الأول: معلومات عامة عن الطالب/الطالبة الثاني: ثلاث حقول ونتطلب كل عبارة اختيار واحد من الإجابات (كثيرًا جدًا، كثيرًا، قليلًا، نادرًا، أبدًا ) أ) "5" عبارات حول وسائل التواصل الاجتماعي واستعمال الرموز التعبيرية وتأثثرها على ب) "8" عبارات حول لغة الإيموجي ج) "7" عبارات حول الترجمة والرموز التعبيرية.

3.2 الفرضية: تفاعل اتجاهات الترجمة الجديدة مع الجيل الرقمي لتوظيف لغة رمزية تعبيرية موحدة في التزجمة للتواصل البسيط دون الحاجة لمعرفة لغة الآخر ومستمدة من نقافات متعددة تعمل جنبًا إلى جنب مع اللغة الطبيعية. 4.2

- - تتبع تطور وتأثير الرموز التعبيرية على اللغة وبالتالي نأثير هذا النوع من التواصل على الترجمة مع ظهور تطبيقات بذللك. - معرفة وسيلة التواصل الرقمي في ظل نمط حياتتا التواصلية المعاصرة. - مدى تطويع الصورة ضمن مفهوم الإنفرادية لتتفاعل مع الآلة والعكس صحيح. 3. اللغة: اللغة الطبيعية عبارة عن نظام رموز صوتية تكوّن أداة تواصل بين أفراد مجتمعها لأداء معان محددة. كانت اللغة ولا تزال، مجال أبحاث عدّة علوم ومنها: (اللسانية، والاجتماعية، والنفسية، والطبّ وغيرها) ولذلك أعطيت تعريفات عدّة مختلفة،

9 نشر رابط الاستبانة عبر وسائل التواصل الاجتماعي والبريد الإلكتروي على عدد كبير من الجامعات العبية ولكن كانت الاستجابة معدومة وقد تم توزيع

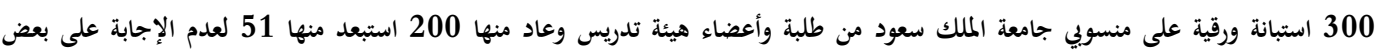
العبارات ، واستجاب إلكترونيَّا 100 ليكون المجموع لعينة الدراسة 249. 
باختلاف العلوم التي يُنظَر منها إليها، ومن هذه التعريفات: "اللغة ظاهرة بسيكولوجيّة اجتماعيّة ثقافية، لا صفة بيولوجية ملازمة للفرد. تتألف من مجموعة ريوز صوتيّة لغوبية، اكتَبَت، عن طريق الاختبار، معاني مقرَة في الذهن. وبهذا النظام الرنزي Michael الصوتيّ، تستطيع جماعة ما أن تتفاهم وتتفاعَل."10. يعتقد مايكل توماسيلو Tomasello في الغالب تتم عن طريق الصوت (Pika، Mitani؛S. ، (2006) (J. C.). فهل تحولت اللغة من رموز صوتية إلى رموز تصويرية ضمن العملية المشار إليها أنفاً؟

1.3. الاتصال: لا قيام للجماعة دون تفاعل اجتماعي مباشر (وجهًا لوجه) أو غبر مباشر (المراسلات الكتابية) ، وعليه فالاتصال هو تبادل الأفراد للمعلومات الرمزية والتي تتنقل عبر رسائل لفظية: نقل المعاني والأفكار في صورة رمزية لغوية. وغير لفظية: رسائل باستخدام الإيماءات والإشارات من خلال تعبيرات الوجه والجسد،.. إلخ. كان الاتصال بين البشر في مرحلة ما قبل اختراع الكتابة شفهيًا فقط، وبعد اختراع الكتابة قبل حوالي خمسة آلاف عام كانت الرسومات والنقوش على الأحجار هي الوسيلة الأحدث، ومع صناعة الورق بدأت الدول القديمة الكبرى كالصّين ومصر بتطوير وسائل جديدة للتواصل؛ حيث تمّ وضع أول خدمة بريد في الصين وكانت خاصّةً بالدولة فقط، واستخدم ورق البردى على نطاق واسع في مصر الفرعونية. وقد شهر القرن الثاني الميلادي طفرةً في وسائل الاتصال في العالم؛ حيث اخترع الصينيون الورق بشكله الحديث، كما طوّروا أوّل مطبعةٍ خشبيّةٍة، ولكن لم يتطوّر الأمر كثيرًا من حيث السرعة في نقل المعلومات إلّا في حالات استخدام الحمام الزّاجل بين أرجاء الدول المختلفة، وذلك حتى ابتكار نظام التلغراف عام188811، وقد أدّى اختراع الهاتف 1874 إلى تغيير شكل الحياة اليوميّة في العالم إلى 
جانب ثَوسعة الثبكات حول العالم وإضافة شبكات الراديو إلى عمل الهواتف. حدثت ثورة في مجالات الاتصالات في القرنين العشرين والواحد والعشرين، وذلك باختراع التلفاز ومن بعده استخدام اللّيزر في مجال الاتصالات، وتطوير شبكة الإنترنت حول العالم، كما تمّ إطلاق الأقمار الصناعيّة المُخصّصة للاتصالات. ومع كل هذه التطورات التكنولوجية تعتبر اللغة أهم وسائل الاتصال التي يستخدمها الإنسان في التفاعل مع غيره من بني جنسه ومشاركتهم خبراتهم مما أدت إلى قيام مجتمعات، لكل مجتمع ثقافته التي تميزه عن غيره. 2.3. الكتابة: لا يمكن الجزم بالقول عن نثأة الكتابة في ضوء المستجدات والاكتشافات العلمية المتتابعة. ولكن استطاع الإنسان أن يضع للغته نظامًا كتابيًا بهدف ترميز هذه اللغة في شكل خطي، ويتم ذللك من خلال نرابط مجموعة من الحروف، بحيث يكون لكل حرف صوت لغوي يدل عليه. تتقسم أنظمة الكتابة 12 إلى: ألفبائية Alphabetic system : يكتب الحرف ثنَّ يحرك بواسطة أحد حروف المد، منل الألفبائية اللاتينية. أبجدي Abjad system : يكتب الحرف ثم يحرّك بواسطة إحدى العلامات الفرعية، منل الأبجدية العربية. > مقطعية Syllabic system : يكتب الحرف الصامت وحرف المد في حرف واحد، منل نظام الكانا في اليابانية. أبوغيدا Abugida system : يدمج الحرف الصامت وحرف المد في حرف واحد إذا أتى حرف مد بعد حرف صامت، منت أبوجيدا التانا. النظام الفكري Ideographic system : فيه يعبر عن الكلمة بأحد الرسوم، ويعد أصعب أنظمة الكتابة في العالم، مثل الصينية المبسطة والصينية التقليدية. إن كثيرًا من اللغات ليست لها أنظمة كتابية، ولذا يتجه علماء اللغة في الغالب إلى استخدام رموز الألفباء الصوتية لتدوين الأصوات الكلامّية. كما يدرس علماء اللغة أيضا اللغات ${ }^{12}$ www.omniglot.com. 
الميتة لتنبّع نشوء اللغات الحديثة. ولكن قد يجد علماء اللغة أيضًا في أدوات التواصل الحديثة مثل الإيموجي وسيلة قد تُنْهِ في حل مشكلة التواصل مع الأقليات اللغوية والتي ليس لها نظام كتابي وفي نفس الوقت قد تساهم بشكل كبير في اندثارها. 3.3. الآلة، الدماغ والإسسان: تفعّل معالجات اللغة في الدماغ الترميزات اللغوية للتحدث والفهم والقراءة والكتابة بطريقة سريعة ودقيقة. نختار كلمات لإيصال المعنى الذي نقصده للمستمع أو المتلقي، بوضع صوت لكل حرف في الكلمة. ونبني نظامًا نحويَّا يربط الكلمات ببعضها البعض وحدودًا نغمية لإيصال أو نقل البناء النحوي. نترجم كل هذه المعلومات إلى أجهزة نطق :حركة الفم والفكين واللسان والحنك والحنجرة ،إلخ.. يتم تتظيم الكل على حدة وعلى أساس مليون من الثانية لكي نتتج حوالي ثلاث كلمات في الثانية أو صوت واحد بمعدل كل عُشُر من الثانية13. هذا في مجال الثفوي فكم نستغرق في الكتابة؟ ولذلك إنسان العصر الرقمي يسعى للوصول بالكتابة إلى سرعته بالنطق من خلال أدوات منل الإيموجي. وفي الواقع الكتابة أصعب بكثير في القياس ، ولكن في الكلام ينبادل المستخدمون ستة مليارات إيموجي يوميَّا بحسب تقديرات رسمية. فكم كلمة يتبادلون ؟ هناك العديد من الدراسات في هذا الإطار ومنها أن الثخص يتكلم بمتوسط 2034 كلمة،14، في اليوم. 4.3. مقارية لغوية: القدرة على الكلام هي واحدة من المكونات الأساسية للحياة البشرية. لذلك فقد وظَّف الإنسان التقنية لمعالجات اللغة الطبيعية من خلال واجهات التخاطب الصوتية بين الإنسان والآلة، وتتطلب هذه الواجهات تقنيات إنتاج الكلام من الحواسيب (تركيب الكلام)، وتعرف الكلام من قبل الآلة. وأقسام الكلام في اللغات بشكل عام فئتين المحتوى functional words (أدوات (الاسم، الفعل، الظرف، الصفة) والوظيفية)content words التعريف، التتكير، حروف الجر، الضمائر ، أدوات الوصل). إذًا هل لغة الإيموجي بمكنها أن تغطي جميع أقسام الكلام؟

\footnotetext{
${ }^{13}$ https://www.marefa.org/\%D9\%84\%D8\%BA\%D8\%A9

${ }^{14} \mathrm{https}: / /$ languagelog.Idc.upenn.edu/nll/?p=4488

${ }^{14}$ https://www.theguardian.com/notesandqueries/query/0,5753,-25335,00.html
} 
الإجابة في تقديري ليس بعد بيد أنها نسهّل لغة التواصل، إذ قد لا يعرف المستخدم لغة غير لغته الأم، ولكنه بتمكن من التواصل إلى حدّ معيّن مع مستخدم ثان في بلد آخر لا يعرف لغته من خلال استخدام الرموز ـ وهناك بعض نواتج الإيموجي الحالية ومنها: - الوجوه المبنسمة هي الرموز التعبيرية الأكثر استخدامًا ، يمكن أن تمثل الأشخاص والأماكن والحيوانات والأشياء والأعلام والرموز ...إلخ. عن طريق إدخالها في رسالة. - يوجد الآن حوالي 2808 رمز إيموجي، ويمكن أن تنشأ منها محادثة تحمل رسالة لأي شخص بلغة أخرى، ولقد نم إنشاء تطبيق لتحويل معظم كلمات العبارة الكتابية إلى رموز إيموجي : أنظر التطبيق التالي الأي يمكن تلخل الكلمة ويحولها إلى رمز

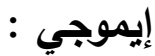
https://meowni.ca/emoji-translate/ ويمكن للك أن تخلق للك تطبيقك لترجمنك الخاصة وفق التالي: https://lingojam.com/edit/8103d913a4ae712698383e0cff42a3a9

وربما يمكن تطويره بلغات أخرى وعندها قد تصبح هذه التطبيقات الأكثر استعمالًا إن لم تكن دون سواها للتواصل بين جيل الثباب الحالي وبتطبيقات أكثر دقة مع الأجيال القادمة. - ترجم الفنان الجرافيكي جو هول Joe Hale 15 عام 2015م، رواية: "أليس في بلاد العجائب Alice's Adventures in Wonderland " للكاتب لويس كارول Lewis Carroll's بينوكيو وبيتز بان. 5.3 التغيير اللغوي ظاهرة طبيعية ومستمرة، ومرد هذه الظاهرة إلى مجموعة من العلل أو العوامل، وتصنف بعض الدراسات العلل أو العوامل التي تقع وراء التغير في اللغة إلى أربع:

${ }^{15}$ https://www.vice.com/en us/article/qkwj9v/author-translates-all-of-peter-pan-into-emojis 
البنيوية، والعلل الاجتماعية، والعلل السيكولوجية، والعلل الفسيولوجية (مصطفى زكي التوني، 1993) وقد نضيف العلل التقنية (الذكاء الصناعي).

6.3. لغة وسائل التواصل الاجتماعي التواصلية: تحتوي معظم وسائل التواصل الاجتماعي نصوص Textsوصور Pictures وفيديوهات Videos وتقبل وسطها لغة جديدة للحوار وشكل مميز: الرموز التعبيرية Emojis، وعند الحديث عن نشأة الرموز التعبيرية، يبرز السؤال: هل تأثز (ثجيكتا) الياباني بطريقة كتابة لغته اليابانية خصوصًا القديمة منها التي تقوم على الثكل التصويري للكتابة (ولمزيدٍ من التعرف على اللغة اليابانية يمكن الرجوع للموقع الإككتروني 16) لينتج لنا الرموز التعبيرية؟ إذًا كيف نشأت هذه الرموز؟ صمح (شيجتاكا كوريتا Shigetaka Kurita) الرموز التعبيرية الأولى والتي بلغ عددها حينها 179 رمزًا على ما لا يقل عن 5 أثنكال تمثل مراحل القمر، و 3 أثكال لساعات (ساعة يد، وساعة حائط، وساعة رملية)، وشكلين لشمسيتين إحداهما مفتوحة والأخرى مغلقة17. وكان أول استخدام للرموز التعبيرية "emojis" لهاتف ياباني الصنع في فبراير 1999. يوجد الآن أكثر من 2000 من الرموز التعبيرية، وتتير بعض التقديرات إلى أن أكثر من 90\% من مستخدمي الإنترنت يستعملونه 18. إن إعادةً صياغة كلمة واحدة يستغرق الكثير من الوقت والتعليم، أمَّا الرموز التعبيرية فهي تختلفُ في صباغتها، وعليه نلاحظ بأن جميع أنظمة تتغيل أجهزة الكمبيوتز المحمولة وهواتف الجوال وحتى الإنترنت تعتمدُ على "يونيكود الرقمي للشركات التي تضيف صورة تتتاسب مع رؤيتهم الجمالية وتوجهاتهم، إلَّ أن عرضَ الصورة التعبيرية غير ثابت في كلٍ الأحوال، وبالتالي من السهل إعادة رسم الصورة وفق تعديلات البرمجة.

${ }^{16} \mathrm{http} / / /$ www.nippon.com/ar/features/h10006

${ }^{17} \mathrm{https} / / /$ web.archive.org/web/20160610220635/http://ignition.co/105

${ }^{18} \mathrm{http}$ ://www.lemonde.fr/pixels/article/2015/05/07/lol-et-omg-menaces-par-les-emoji-seloninstagram 4629489 4408996.html

19 معيار يمكّن الحواسيب من تمثيل النصوص المكتوبة بأغلب نظم الكتابة ومعالجتها، بصورة متناسقة. 
تعتمد اللغة البابانية20 والمندرانية الصينة21 على سبيل المثال كلغات على الكتابة الصورية وليست الأبجدية فلها حوالي 3 آلاف شكل، وتحتوي أحدث نسخة من "يونيكود" على أكثر من 128 ألف رمز، والتي تغطي 135 طريقة كتابة حديثة وتاريخية، أمَّا الرموز التعبيرية فإنها تضيف رقمًا أكبر من ذلك كل عام. يتضح مدى انتشارها في عام 2015 عندما تم اختيار قاموس أكسفورد22 الرموز التعبيرية المعروفة باسم "الوجه مع دموع الفرح" باسم "كلمة السنة" وتم اختيار رمز تعبيري (إيموجي) ليكون هو 》اكلمة العامه، يقول (كاسبار جراثوول)، رئيس موقع قواميس أكسفورد الذي تديره جامعة أكسفورد، أن النصوصن الأبجدية التقليدية ازتاضل من أجل مواكبة المطالب السربعة للتواصل في القرن الحادي والعشرين، التي تركز على الرئيةه. لكن السؤال المتداول وبقوة: هل تغير 》الإيموجيه في وسائل التواصل الاجتماعي يمنل لغتتا؟ أصبحت الرموز التعبيرية (الإيموجي) شكلًا غنيًّا للتواصل يتجاوز الحدود اللغوية، وباتت مهمةً للجيل الرقمي الحالي وبالنسبة للكثيرين، وتعني هذه الرموز (الإيموجي) أكثر من مجرد رمز يعكس الحالة المزاجية أو الحيوية للشخص. ويمكن تقديم الرموز الخاصة بثقافة ما، كما هو الحال مع الرمز الذي يمثل فتاة محجبة من الثقافة الإسلامية؛23، فهل سيأتي يوم تصل فيه مثل هذه الرموز إلى حدِّ الكفاية التواصلية دون الحاجة لترجمة؟ "عندما تكون الردوز التعبيرية معزولةً، فإنها تحكمها في الدقام الأول قواعد بسبطة تتعلق بالهعنى وحده، بلون القواعد الأكثر تعقيدًا، مثال وفقًا للبحث الذي أجراه (تايلر شنبيلن)، غالًَا

20 اللغة اليابانيّة تستخدم ثلاثة أنواع من الحروف، حيث يعود أصل الرموز المُستخدمة في كتابة اللغة اليابانيّة إلى الصين؛ إذ نشأت اللغة في الصين قبل

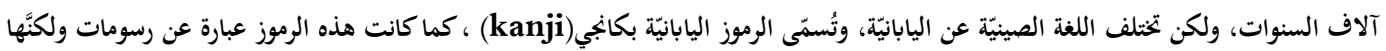

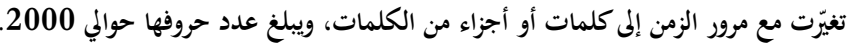

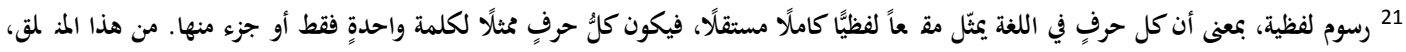

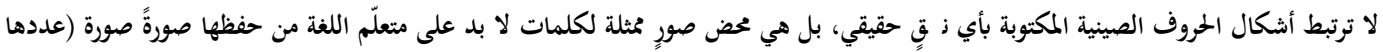
بالآلاف)، وكثيرًا ما تكون أشكال هذه الحروف مرتب ة بالمعاني التي تمثلها، كالأجسام الفيزيائية. 22 https://en.oxforddictionaries.com/word-of-the-year/word-of-the-year-2015

23 جاء الحجاب الإسلامي من بين الرموز التعبيرية (الإيموجي) الجديدة المدرجة في أحدث إصدار لايونيكوده)، رقم 0.10. 
ما بخلق الناس سلاسل من الرموز التعبيرية التي تشترك في معنى مشترك، مثل تحبة عبد

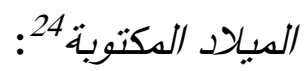

وإحدى تساؤلات الدراسة بطرحها أيضًا (مارسيل دينسي)، " تزايد استخدام الرموز التعبيرية في مجالات أخرى من التواصل، من الحملات السياسية إلى الإعلانات التجارية، مما بثير سؤالًا Marcel Danesi, أساسيًّا: هل بدأت الكتابة الأبجدية تختفي، لتحل محلها أثكال بصرية؟ $\cdot(2016$

7.3. اللغة والتقنية : شكلت نظرية المعلوماتية، ولاسيما الحوسبة، تحديًا معرفيًا بالنسبة للغة منذ أربعينيات القرن العشرين، ورأى (ميلكا افيتش) Milka Ivit في كتابه "اتجاهات البحث اللساني" Trends in Linguistics أن هذه النظرية طوّرت الدرس اللغوي المعاصر بتعاضدها مع المناهج المعرفية الحديثة منل اللسانيات البنيوية " ويضيف" أن اللغةَ نظام يتشكل من وحدات محددة تحديدًا دقيقًا، ويرتبط بعضها ببعض بعلاقات منبادلة، وأن هذه الوحدات محدودة من حيث العدد، وليست كبيرة، ولكن نوليفاتها تمتثُّ إلى ما لا نهاية. واعتمادًا على هذه المقولة نجح علماء الرياضيات في تطبيق منهجم التحليلي على اللغة". نشرت صحيفة الديلي ميل Daily Meal في تقرير بتاريخ 2017/12/15م أجزاءً من محاضرة براين جونسون Bryan Johnson الرئيس التنفيذي لثركة Kernel برشلونة 2016، حيث تطرق للمشاريع البحثية القائمة في شركته التي تسعى لزرع شرائح في أدمغة البشر، بحيث تمكنهم من التخاطب العقلي والتواصل بلغة الصمت عبر الثرائح المزروعة في الأدمغة وبإمكان البشر الوصول لأية معلومة في الإنترنت عبر تلك الثرائح

${ }^{24}$ http://www.visuallanguagelab.com/

${ }^{25}$ https://kernel.co/ \& https://bryanjohnson.co/ 
المزروعة في الدماغ، وحل المسائل المعقدة في لحظات وحذف ذكريات معينة من الدماغ وربما يقودنا ذلك لصناعة ذكريات وأحداث وهمية في أدمغة بشر المستقبل. 4. دراسات:

الدراسة 1: وفقًا لاستطلاع226 ـ FDJ كثف عن نتائج رأي أجرته قناة Opinion Way عن

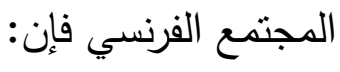
- - الوجوه التعبيرية الصغيرة معروفة بنسبة 90٪ من الفرنسيين و 74\% منهم سيكونون قادرين على شرح ما هو بالضبط. - 84\% منهم استخدموا الرموز التعبيرية مرة واحدة على الأقل. - 95\% بيتخدمونه الصغار ، 73٪ من الأشخاص الذين تتراوح أعمارهم بين 50 وأكثر - تستخدم من قِبَلِ الجميع وفي جميع الفئات العمرية ، في السياقات الشخصية (81٪) إلى أصدقائهم) والمحترفين 63\% إلى زملائهم •

- يستخدم الفرنسيون حوالي 6 رموز تعبيرية في المتوسط يوميَّا، أي حوالي 2 لكل رسالة. - يبرز الثباب من خلال استخدامهم الأكثز تكرارًا: 15 رمزًا تعبيريًّا يوميَّا للأطفال الذين تتراوح أعمارهم بين 18 و 24 عامًا ، و 10 للكبار بين 25 و 34 عامًا. - الابتسامة هي الأكثر استخدامًا (46\%) ، مرتبطة بالغمزة المبتسمة (46\%). تتتهي الرموز التعبيرية بابتسامة عريضة في المراكز الثلاثة الأولى (36\%). - - بالنسبة لغالبية الفرنسيين ، فإن الرموز التعبيرية هي العنصر الذي يعمل على إكمال النص، لإعطائه النغمة: أنه يقوي الهدف ، ويوضحه ، ويؤكد المعنى (75\%). لكن نسبة كبيرة من المجيبين تستخدمها أيضًا لتوفير الوقت (26\%). - يمكن أن يعبروا عن مشاعرهم بسهولة أكبر (61\%) ${ }^{26} \mathrm{https}$ ///www.ladn.eu/nouveaux-usages/etude-marketing/les-emoticones-ca-change-quoi/ 
- تعد الرموز التعبيرية شكلًا جديدًا من التواصل لـ 57٪ من الفرنسيين (68\% بين

$$
\text { الأشخاص دون سن 35). }
$$

- لكن الرموز التعبيرية تثير بعض المخاوف: 51\% فقط من الفرنسيين بشعرون أنها تثري الحوار • على العكس من ذلك ، فإن 46٪ يخشون من أن الرموز التعبيرية تهدد الكفاءة اللغوية للأجيال القادمة و 43\% يشعرون أنها تفقر اللغة الفرنسية. Elisabeth Stark الاراسة 2: في دراسة لفريق من جامعة زيورخ بإدارة إلزابيت ستارك بعنوان "What’s up, Switzerland ?"، تظهر بأن النساء أكثر استخدامًا للتعابير من الرجال وأن الأجيال كلما كانت شابة كان استخدامها للتعبير أكثر 27. دراسة 3: تشير عالمة النفس ليندا كاي Linda Kaye28، مؤلفة دراسة حول دور Kaye, L. K., Malone, S. A., \& Wall, H. J., ) الرموز التعبيرية في السلوك البشري 2017)، إلى أن العديد من المستخدمين الذين شاركوا في أبحاثها أبلغوا أيضًا عن استخدامهم للمساعدة في جعل الرسالة المكتوبة أقل غموضًا. 1.4. عن الإيمويجي: أفرز تطور المعلوماتية والرقميات وعالم السايير واختراعاته وإضافاته وتطبيقاته المتلاحقة على هواتفنا الذكية مؤخرًا لغة إيموجي Emojis عبر تطبيقات الرسائل المختلفة، وعليه فالرموز التعبيرية (الإيموجي"Emojis) هي رموز وصور تعبيرية ثابتة أو متحركة مختلفة ضمن منصات وسائل التواصل الاجتماعي ما بين الأشخاص والمهن والرموز الخيالية والحيوانات والمأكولات والمشروبات وأعلام الدول بالإضافة إلى الوجوه الضاحكة، ويستعملها جيل الألفية الثانية بكثرة للتعبير عما يريد أن يقول بعيدًا عن كتابة النصوص. يوضح عالُِّ الاجتماع أندريه غونترت André Gunthert29 ، بأن الرموز التعبيرية تعطي قيمة مضافة عاطفية للغة، من خلال أن لديها ثناثة أبعاد أساسية:

\footnotetext{
27 https://www.unine.ch/unine/home/pour-les-medias/communiques-de-presse/whatsapp-les-emojis-et-lorthogra.html

${ }^{28}$ https://www.edgehill.ac.uk/psychology/people/academic-staff/dr-linda-kaye/

29 https://c-marketing.eu/emoji-le-nouveau-langage-des-emotions/
} 


$$
\text { > > الجماليات - لأن رسالة مع الصور أجمل ، فمن الزخرفية. }
$$

> السيمائية - يمكن للصورة أن تعني أثنياء كثيرة ويمكن تفسيرها على نطاق أوسع من

$$
\text { رسالة اللغة. }
$$

وهكذا ، الرموز التعبيرية تسمح للمستخدم للعب مع الكلمات والتعبير عن أنفسهم تصويريًّا، لكن الرموز التعبيرية ليست لغة بمعنى الكلمة. تقول سوزان هيرينج Susan Herring "الغة جديدة مبسطة تم أنثاؤها عندما بعبش أشخاص بلغتين معًا".

1.1 .4 نجاحات الإيموجي: أن الثعبية التي حظيت بها الرموز التعبيرية -خصوصًا

لاى الشباب- إلى جانب أنها أصبحت إحدى وسائل التفاهم التواصلي بين اللغات جعلت بعض المؤسسات منها مصدرًا اقتصاديًّا حيث يمكن بيع أو

$$
\begin{aligned}
& \text { شراء رمز ما. وهذه بعض إفرازات ظهور الإيمويجي: } \\
& \text { - أصبح للرموز التعبيرية يومها العالمي في } 17 \text { يوليو } 2015 .
\end{aligned}
$$

- ترجمة الكتاب المقد إلى صور توضيحية Emoji Bible ويستخدم أكثر من 80

$$
\text { رمزًا تعبيريًا. }
$$

- وضعت في البرازيل شركة Live TIM وشركة Live Artplan تصورًا لبرنامجٍ إضافيٍٍ يعمل على ترجمة الرموز التعبيرية إلى أصوات لتحسين فهمها للمكفوفين

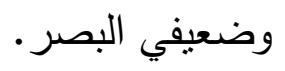

- أنشأ كارل لاغرفيلد Karl Lagerfeld في عام 2014 أبجدية الرموز التعبيرية الخاصة به: EmotiKar| (21

the emoji دخل صالات العرض منتصف أغسطس 2017 فيلم الرموز التعبيرية Sony Pictures Animation and " فيلم أميركي ثلاثي الأبعاد من أنتاج "movie" 
Columbia Pictures الذكي الذي بات جزءًا حيويًّا من وعينا وشخصيتنا، وتدخل الكاميرا رفقة نقلات متسارعة إلى التطبيقات لتصل إلى مدينة تيكستوبوليس النابضة بالحركة وحيث نتشط أنشهر الإيموجي في شخصيات ناطقة متفاعلة محبة وعطوفة ومضحكة تغري مستخدم الهاتق بالاستفادة منها، ويعرض الفيلم بطريقة ذكية أنواعًا ليست شائعة بين الإيموجي مُحِنًا مستخدم الهاتف على توظيفها بعد أن يتعود على معانيها. تبحث وكالة ترجمة في لندن، Today Translation، عن موهبة جديدة: مترجم الرموز التعبيرية (أو الرموز) ذذكرت مديرة الوكالة، جورجا زيلينسكيني، لبي بي سي أنها نظرت في ترجمة الرموز التعبيرية "للنمو المحتمل"، بالنظر إلى الاختلافات في الاستخدام بين كل بلد32. إضافيّا يعمل على نرجمة الرموز التعبيرية إلى أصوات لتحسين فهمها للمكفوفين وضعيفي البصر • n

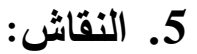

تتامي أعداد صور الإيموجي ورموزها ودخول حركة الرسوم المتحركة على بعضها، ما يجعل المرء يتساءل أين يمكن أن تقف هذه اللغة التي لا تحتاج حروفًا ولا قواعد ولا تتقيط ولا كتابة ولا بلاغة ولا إنشاء؟ وصعوبة الكتابة في بعض اللغات كاللغات المقطعية منل الصينية واليابانية أو الأبجدية منل الحركات في الفرنسية أو العربية. لقد سبقت الكتابة التصويرية الأبجدية، وكانت الصورة تستخدم للتعبير عما يجول في خاطر الإنسان، وفي سرد القصص. كما هو الحال في الكتابة الهيروغليفية وبعد ذلك ساد الحرف آلاف السنين..والآن، عاد الإنسان إلى الكتابة بالصورة في عصر الرسوم التعبيرية "إيموجي". يسكن العالم أكثر من 7 مليار ونصف (منهم نحو 4 مليار يستخدم النت- 3مليار نَشِط على وسائل التواصل

\section{${ }^{32}$ https://www.lemonde.fr/big-browser/article/2016/12/14/entreprise-cherche-traducteur- parlant-couramment-l-emoji 5049037 4832693.html}


الاجتماعي - 5مليار لديهم جوال- حوالي 3مليار يستخدمون الجوال لتصفح التواصل الاجتماعي)...وعليه فإذا قارنا فسنجد أن 50 \% من سكان الأرض لايه إمكانية النت فقط وهنا نقول لا يمكن أن تككن الإيموجي لغة للجميع الّا إذا أصبحت خدمة النت لكل شخص عليها.

1.5. تطور استخدام الرموز والمختصرات للكلمات بدءًا من ظهور الثبكة العنكبوتية: Е الجديد في لغة جيل الثاب: أن طبيعةَ الإنترنت باعتبارها وسيلةً اتصال سريعة الإيقاع قد واكبتها محاولات لفرض عدد من المفردات السريعة والمختصرة للتعامل بين الثباب. أولًا: استخدام اختصارات في المحادثة عبر الإنترنت للتعبير عن أفكاره مثل:

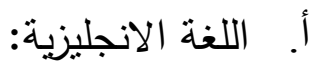

\begin{tabular}{|c|c|c|}
\hline الجملة & المعنى & الاختصار \\
\hline Laughing Out Loud & يضحك بصوت عالي & LOL \\
\hline Be Right Back & سأعود قريبًا & BRB \\
\hline Take Your Time & خذ وقتاك & TYT \\
\hline Welcome Back & أهلاً بعودتك & WB \\
\hline
\end{tabular}

جدول2: مختصرات عبر النت لعبارات باللغة الاتجليزية ب. اللغة العربية: يستعمل فئة من الثباب العربي حروفًا للغة العربية ورموزًا وأرقامًا 33،

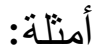
الحاء "7" والهمزة "2" والعين "3" :فكلمة "حوار" تكتب " 7war" وكلمة "سعاد" تكتب 34 "so3ad"

${ }^{33}$ https://groups.google.com/forum/\#!topic/shehryar0/qlcme9V3Bx0 34 وقد انتشرت هذه اللغة بين الـ لاب المغتربين، والسبب يعود إلى أن الأجهزة ا هولة والمتصفحات للإنتزنت لديهم في تلك البلدان لم يتوفر فيها لوحة مفاتيح بالعربية. 
ثانيًا: تزايد وتنوع استخدام وسائل التواصل الاجتماعي وتعودهم على وسائل المحادثة الكتابية "الثات"، جعل منهم جيلًا يتسابق وبشغف كبير للانتقال من الاختصارات إلى لغة "الإيموجي" التعبيرية. • يحاول مستخدمو الإنترنت منذ إنشائه تقصير النصوص النصية من أجل تسريع عملية التواصل وسهولة التعبير، لذا يتم التعرف على العديد من الكلمات بين المستخدمين، دون الحاجة إلى القواميس اللغوية أو توحيد الصيغ وكان من أهمها حسب ترتيب ظهورها:

- مرق كتابة كلمات كثيرة متعارف عليها بين المستخدمين، منل م - عبر المستخدمون باختصارات عدة مع ظهور الهواتف المحمولة والتواصل عبر الرسائل القصيرة SMS لتقليل عدد الحروف قدر الإمكان والتي لها عدد معين من الحروف (العربية 70 حرفًا، الانجليزية 160 حرفًا) وذلك لتقليل تكلفة الإرسال عبر الثبكات.

- منذ سنوات قليلة ومع زيادة مستخدمي شبكات التواصل الاجتماعي ظهرت الرموز التعبيرية بالثكل الجديد المطور من صور جذابة والوان براقة وحركات كارتونية ممتعة مما جعل الصغار والكبار يستخدمونها في التعبير بها بدلًا من النصوص والكلمات. 


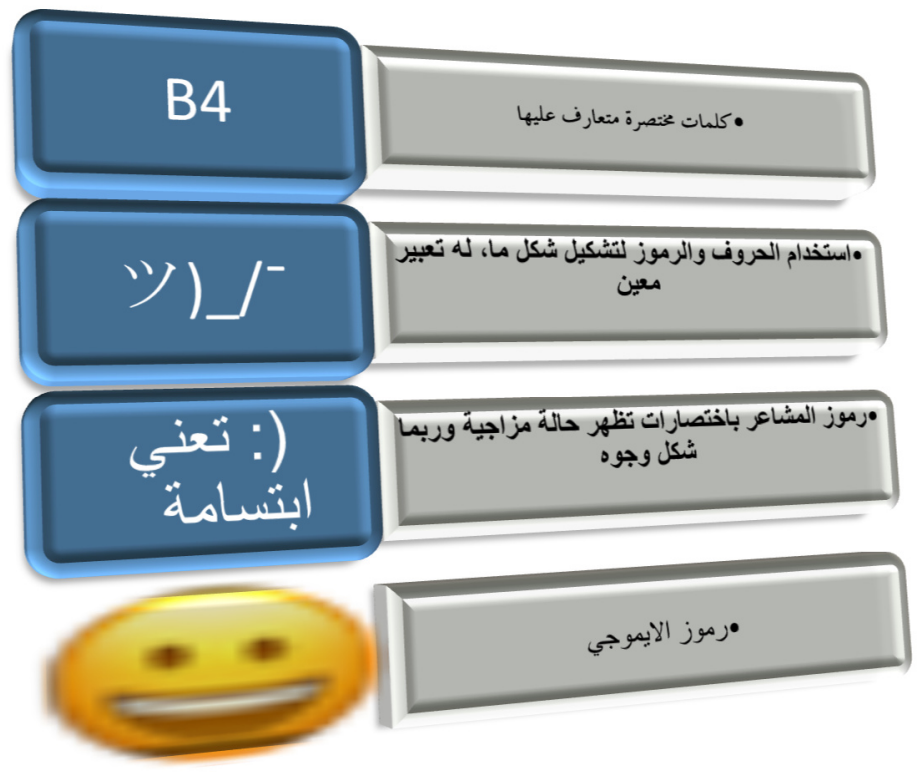

رسم 2: تطور استخدام الرموز والمختصرات للكلمات بدءًا من ظهور الإنترنت

تبدو الرموز التعبيرية سهلة القراءة وكأنها أثياء معروفة للجميع، وبالتالي تقلد في أثكالها الرسومية الأشياء التي يتم تحديدها من خلال إدراكنا البصري. لذلك من السهل فهم معنى الرموز التعبيرية، لأنها تشبه الأجسام المعروفة للجميع إلّا أنه من الضروري مراعاة المعايير

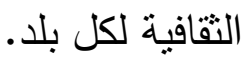

2.5. تطور الصور لنقل المشاعر في التواصل: ولات الصور التوضيحية الأولى التي رافقت النصوص لنقل مشاعر المتحدث مع أول برنامج في جامعة أمريكية في إلينوي عام 1972 حيث بدأت الرموز الصغيرة التي تمثل الابتسامات، ويحاكي الحزن، الخ... حينئ ظهرت الرموز الأولى مع هذا النمط من التواصل. ظهر عام 1982 الرموز التي تتكون من علامات الترقيم. لتمنّل ابتسامة، نستخدم على سبيل المثال نقطة مزدوجة وأقواسًا مغلقة، أنظر الرسم رقم 2. وبالرغم من شعبية تعابير الإيموجي الكبيرة يفضل العديد من الثباب استخدام المحاكاة "ahah" الصوتية (رسائل صوتية لمدة 5-6 ثوان) أو عمليات التعطلّ. على سبيل المثال، بدلًا من تعبيرات البسمة. 
-GIF (graphic interchange format) الثخصية وتعطي للناس وسيلة خفيفة الوزن للتواصل من خلال الرسوم المتحركة. يعتمد نسق الرسومات المتبادلة الامتداد على التسيق الجدولي لحفظ الصور وبضغط خوارزمي مناسب للصور على المساحات الأفقية بلون واحد. - تطبيق35 Stickers : يسمح بالتعبير عن النفس بطرق أكثر ثراءً من خلال توفير ملصقات يمكن استخدامها في محادثاتهم على iMessage. والملصق توضيح مفصل للشخصية التي تمنت العاطفة أو الحركة التي هي مزيج من الرسوم الساخرة و "الرموز التعبيرية" اليابانية

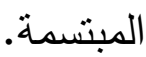
تم نشر الملصقات لأول مرة من خلال تطبيقات الرسائل المحمولة الذي طورته كوريا. طور Naver خدمة الرسائل المحمولة المهيمنة في كوريا الجنوبية. ولقد ساعد مزيج الملصقات من نظام الرموز التعبيرية في كل مكان مع العمل الفني على غرار أنيمي، واستخدامها كبديل لكتابة رسائل أطول في النص الياباني على جذب الجماهير اليابانية. نظرًا لتزايد هيمنة (Russell,. Jon, 2013) Line

وفي عام 2013، بدأت الملصقات في التوسع خارج الأسواق الآسيوية: أضافت Path ملصقات في مارس 2013 كجزء من نظام الرسائل الخاص الجديد ( Engadget. Retrieved 2019)، منبوعة بتطبيقات Facebook وتطبيقات Facebook Messenger المحمولة في أبريل. في يوليو، تم تمديد وظيفة الملصقات لتشمل واجهة الويب الخاصة بـ Facebook، (Cipriani Jason,2019)، بينما أضاف Kik Messenger أيضًا ملصقات.

${ }^{35}$ https://developer.apple.com/stickers/ 
(Russell, Jon, 2013) ظهرت أيضًا الشركات الناشئة المخصصة للملصقات ، مما ساعد في Fortune. Retrieved ) إنتاجها نيابة عن العلامات التجارية كجزء من الحملات الإعلانية. $\cdot(2019$

وجد استطلاع لمستخدمي الهواتف المحمولة عام 2013 أن 40٪ من الذين شملهم الاستطلاع يستخدمون الملصقات على أساس يومي، وبلغت نسبة الإندونيسيين الأكثر استخدامًا في اليوم (46٪)، تليها الصين (43\%)، كوريا الجنوبية (38 \%) والولايات المتحدة (35\%). من بين أولئك الذين استخدموا الملصقات بانتظام، كان 20 \% قد دفعوا ثمن الملصقات أو الرموز التعبيرية في تطبيقات المراسلة المحمولة مرة واحدة على الأقل .(TechCrunch. Retrieved 2019) 6. - مليل البيانات:

تم تقريغ الإجابات لـ249 استبانة وللوصول إلى معطيات لأسئلة الدراسة حول طريقة استعمال الثباب لوسائل التواصل الاجتماعي في التواصل واستخدامهم للغة "الإيمويجي" للتواصل، ومدى توظيف الرموز في الترجمة، فقد أظهرت العبارات المحددة في الاستبانة

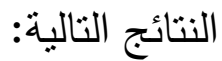
تكونت استبانة الدراسة من 19 عبارة مقسمة على ثناث محاور : 1. وسائل التواصل الاجتماعي (خمسة أسئلة). 2. لغة الإيموجي (سبعة أسئلة). 3. الترجمة (سبعة أسئلة).

وسائل التواصل الاجتماعي : 1. استخدم وسائل التواصل الاجتماعي. 2. أؤيد استخدام وسائل التواصل الاجتماعي في العملية التعليمة 3.سبق أن استفدت من وسائل التواصل الاجنماعي في مقرر دراسي. 
4. أكتب في وسيلة التواصل الاجتماعي بلغة الإيموجي.

5. جميع وسائل التواصل الاجتماعي تستخدم الإيموجي.

لغة الإيموجي : 1. استخدم لغة الإيموجي. 2. تعابير الإيموجي لغة جديدة للحوار.

3. نحتاج رموز إيموجي عربية جديدة تعبر عن بيئتنا وحضارتتا وثقافتتا. 4. يتكلم العالم الإيموجي كلغة موحدة بلا حروف ولا قواعد. 5. تعبر الإيموجي عن معان متعددة كما يحصل في استخدام الكلمات. 6. تؤثز لغة الإيموجي سلباً على اللغة بشكل عام. 7. تساعد لغة الإيموجي على إيصال الرسالة بطريقة أسرع. الترجمة : 1. يمكن أن تحل الإيموجي بدلاً عن الترجمة. 2. يعيق الترجمة الرقمية حاليًا تعبيرها عن المشاعر. 3. يعد تأثير لغة الإيموجي سلبًا على الكتابة. 4. استخدم لغة الإيموجي في التعبير بها مع الآخر الذي لا نجيد لغته بدلاً من الترجمة. 5. اعرف تطبيقات تحوّل النصوص/الكلمات إلى تعابير إيموجي. 6. تخدم الإيموجي الترجمة من خلا تحويل الكلمات إلى رموز إيموجي عبر تطبيقات. 7. أؤيد فكرة تعلم الترجمة باستخدام تعابير الإيموجي. الوصف الإحصائي لاستبانة الاراسة: حجم العينة 249 شخصًا منهم 204 ذكورًا (181.9\%), و 45 أنانًا (18.1\%). المستوى التعليمي: طالب/ة: 208، من حاملي شهادات الدكتوراه: 41 


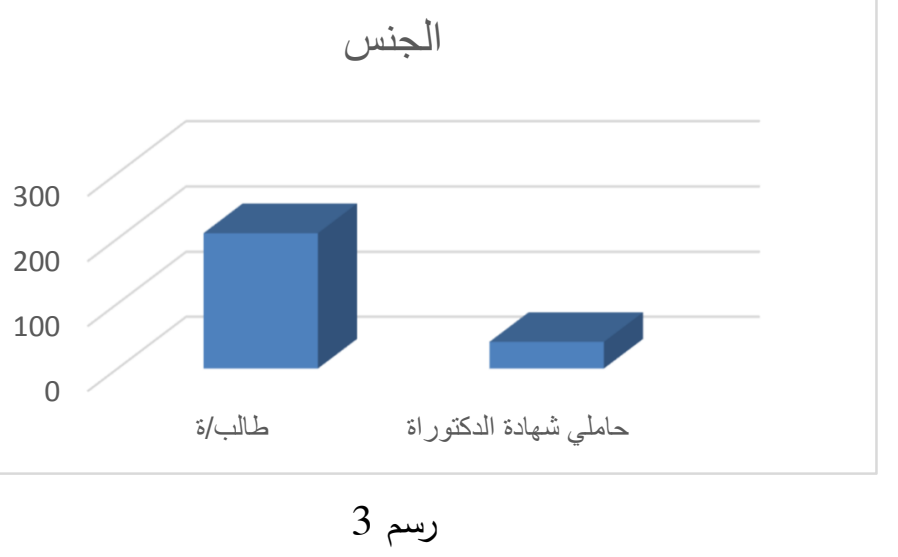

الفئة العمرية

• 160 شخصًا (ما بين 18 إلى 23 سنة).

33 شخصًا (ما بين 24 إلى 29 سنة).

8 أشخاص (ما بين 30 إلى 34 سنة).

9 أشخاص (ما بين 35 إلى 39 سنة).

39 شخصًا (أعلى من 40 سنة).

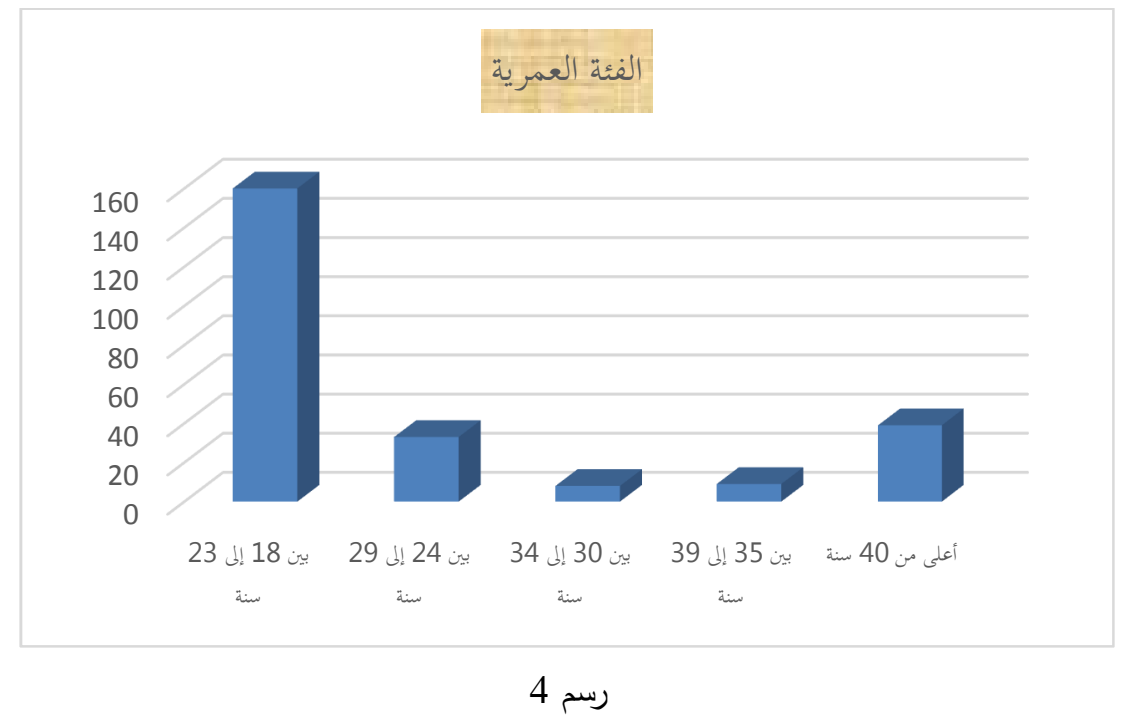


كانت نتائج كل محور وفروعه كالتالي: وسائل التواصل الاجتماعي:

1 ـيستخدم المجتمع وسائل التواصل الاجتماعي كثيرًا جدًا ( 93\%) . 2.يؤيد استخدام وسائل التواصل الاجتماعي في العملية التعليمة (75.1\%)، وسبق أن استفادوا من وسائل التواصل الاجتماعي في مقرر دراسي (69.1\%). يُكتب في وسيلة التواصل الاجتماعي بلغة الإيموجي (52.7\%)، ويُستخدم الإيموجي في جميع وسائل التواصل الاجتماعي بكثرة (77.7\%).

3.استخدام وسائل التواصل الاجتماعي للغة الإيموجي كثير ومستحسن بين فئات المجتمع. لغة الإيموجي: 1.يسخدمها المجتمع كثيرًا (59.5\% )، تعابير الإيموجي لغة جديدة للحوار (69.5\%)، نحتاج رموز إيموجي عربية جديدة تعبر عن بيئتنا وحضارتتا وثقافتنا (62.3\%)، ينكلم العالم الإيموجي كلغة موحدة بلا حروف ولا قواعد (67.2\%)، تعبر الإيموجي عن معان متعددة كما يحصل في استخدام الكلمات (77.9\%)، تساعد لغة الإيموجي على إيصال الرسالة بطريقة أسرع (85.9) 2.يعتقد القليل فقط من المجتمع أنه تؤثر لغة الإيموجي سلبًا على اللغة بشكل عام.

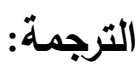
1.يعتقد القليل بأنه يعيق الترجمة الرقمية حاليًا تعبيرها عن المشاعر. ويُعَدُّ تأثنير لغة الإيموجي سلبيَّا على الكتابة. وتخدم الإيموجي الترجمة من خلا تحويل الكلمات إلى رموز إيموجي عبر تطبيقات. وأؤيد فكرة تعلم الترجمة باستخدام تعابير الإيموجي وجميعها معنوية. 2. يعتقد نادرٌ من الناس بأنه يمكن أن تحل الإيموجي بدلًا عن الترجمة بمعنوية. 3. والنادر أيضًا هم مَن استخدما لغة الإيموجي في التعبير بها مع الآخر الذي لا يجيد لغتهم بدلًا من الترجمة وكذلك النادر هم مَن يعرفون تطبيقات تحوّل النصوص/الكلمات إلى تعابير إيموجي وجميعها معنوية. 
التحليل والنتائج:

دراسة المحور الأول: وسائل التواصل الاجتماعي 1. 1 استخدم وبائل التواصل الاجتماعي.

\begin{tabular}{|c|c|c|c|c|c|}
\hline \multicolumn{2}{|c|}{ 95\% فترة ثقة } & \multirow[b]{2}{*}{ المعياري } & \multirow[b]{2}{*}{ الالتحراف } & \multirow[b]{2}{*}{ المتوسط } & \multirow[b]{2}{*}{ 2. العبارة } \\
\hline الألعد & الحد الأدنى & & & & \\
\hline 4.50 & 4.34 & 0.04 & 0.625 & 4.42 & الاجتماعي امتام وسائل التواصل \\
\hline
\end{tabular}

يوضح الجدول 3 أن الاتجاه العام لهذه العبارة (استخدام وسائل التواصل الاجتماعي) "كثير جدًا" وذلك بثقة 95\% في القرار، ولكي نتأكد من هذه النتيجة قمنا باختبارها: هل أن هناك كثيرون جدًا يستخدمون وسائل التواصل الاجتماعي؟ فكانت القيمة الاحتمالية هي 0.000 وبالتالي معنوية الفرضية تشير إلى أن الرأي في هذا السؤال هو استخدام وسائل التواصل الاجتماعي كثيرًا جدًا . كما أننا نجد أن نسبة لا تقل عن 93.6\% وهي نسبة معنوية (القيمة الاحتمالية 0.000) نستخدم وسائل التواصل الاجتماعي بكثرة.

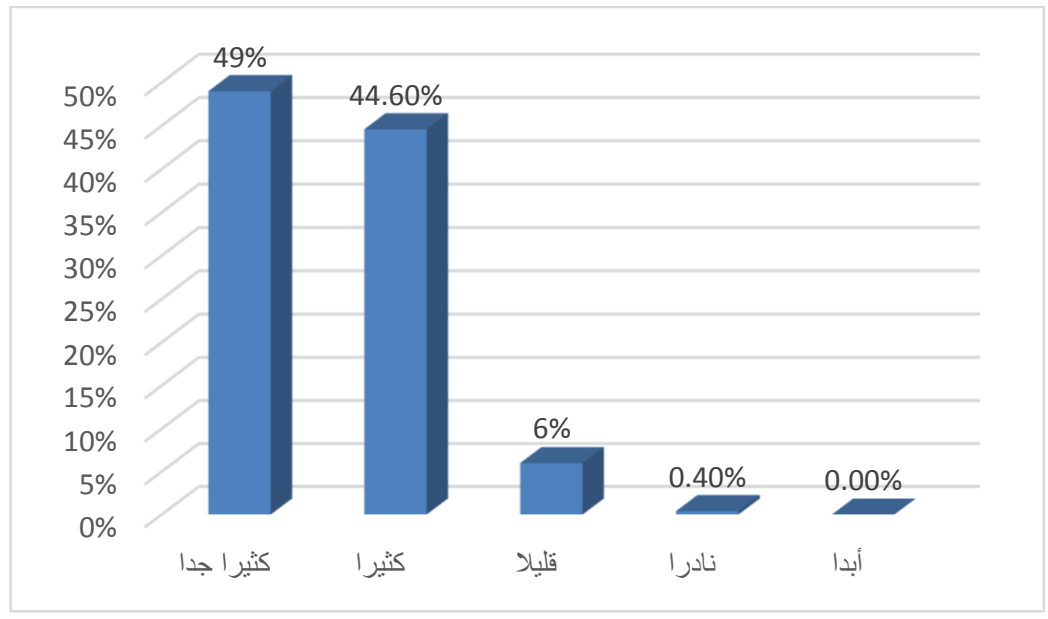

رسم 5 
العبارة (2): أويد استخدام وسائل التواصل الاجتماعي في العملية التعليمة.

\begin{tabular}{|c|c|c|c|c|}
\hline \multicolumn{2}{|c|}{ 95\% فترة ثقة } & \multirow{2}{*}{ الخطأ } & \multirow{2}{*}{ الالمعياري } & \multirow[b]{2}{*}{ المتوسط } \\
\hline الأعلى & الأدنى & & & \\
\hline 4.17 & 3.93 & 0.06 & 0.949 & 4.05 \\
\hline
\end{tabular}

يوضح الجدول 4 أن الاتجاه العام لهذه العبارة تأييد استخدام التواصل الاجتماعي في العلمية التعليمية "بكثرة" (كثيرًا فقط) فقط وذللك بثقة 95\% في القرار، ولكي نتأكد من هذه النتيجة قمنا باختبارها: هل أن هناك كثيرون يؤيدون استخدام وسائل التواصل الاجتماعي في العملية التعليمة؟ فكانت القيمة الاحتمالية هي 0.000 وبالتالي معنوية الفرضية تشير إلى أن الرأي في هذا السؤال هو تأييد استخدام وسائل التواصل الاجتماعي في العملية التعليمية كثيرًا. كما أننا نجد أن نسبة لا نقل عن 75.1\% وهي نسبة معنوية (القيمة الاحتمالية 0.000) تؤيد استخدام وسائل التواصل الاجتماعي في العملية التعليمية.

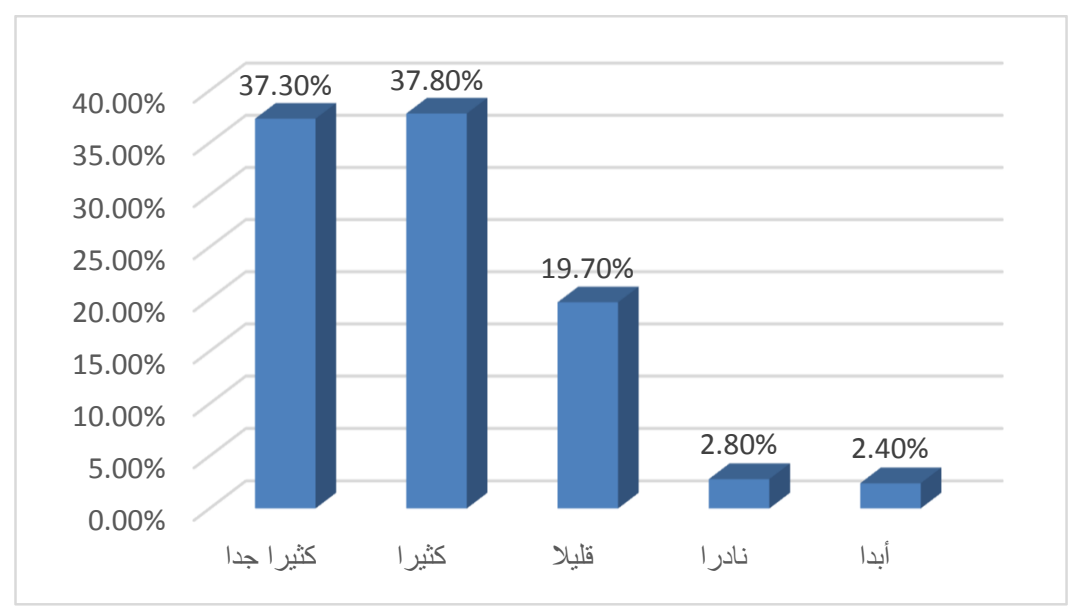

$$
\text { رسم } 6
$$


العبارة (3): سبق أن استفدت من وسائل التواصل الاجتماعي في مقرر دراسي.

\begin{tabular}{|c|c|c|c|c|}
\hline \multicolumn{2}{|c|}{ 95 فترة ثقة } & \multirow{2}{*}{ الخطيأ } & \multirow{2}{*}{ الالحراف } & \multirow[b]{2}{*}{ المتوسط } \\
\hline الأعلى & الأدنى & & & \\
\hline 4.06 & 3.8 & 0.067 & 1.056 & 3.93 \\
\hline
\end{tabular}

جدول

يوضح الجدول 5 أن الاتجاه العام لهذه العبارة بأنه سبق لهم الاستفادة من وسائل التواصل الاجتماعي في مقرر دراسي بكثرة (كثيرًا فقط) وذلك بثقة 95\% في القرار، ولكي نتأكد من هذه النتيجة قمنا باختبارها: هل أن هناك الكثيرون مِمَّن سبق لهم الاستفادة من وسائل التواصل الاجتماعي في مقرر دراسي ؟ فكانت القيمة الاحتمالية هي 0.000 وبالتالي معنوية الفرضية تشير إلى أن الرأي في هذا السؤال هو أنه سبق واستفاد الكثير من وسائل التواصل الاجتماعي في مقرر دراسي. كما أننا نجد أن نسبة لا تقل عن 69.1\% وهي نسبة معنوية (القيمة الاحتمالية 0.000) سبق واستفاد من وسائل التواصل الاجتماعي في مقرر

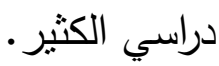

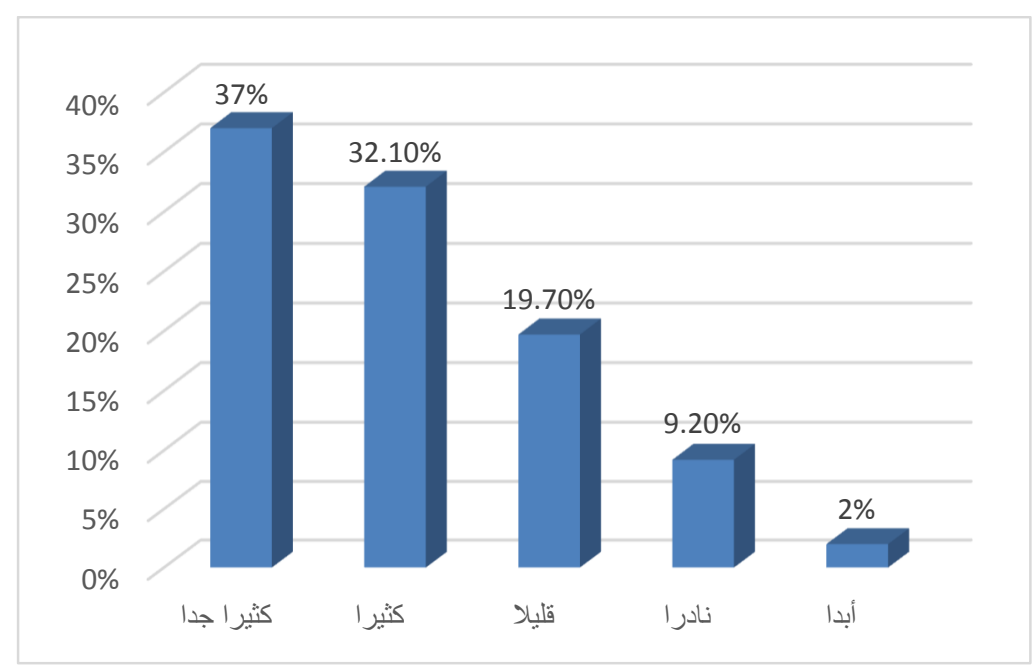

رسم 7 
العبارة (4): اكتب في وسيلة التواصل الاجتماعي بلغة الإيموجي.

\begin{tabular}{|c|c|c|c|c|}
\hline \multicolumn{2}{|c|}{ 95\% فترة ثقة } & \multirow{2}{*}{ الخطأ } & \multirow{2}{*}{ الانحراف } & \multirow[b]{2}{*}{ المتوسط } \\
\hline الأعلى & الأدنى & & & \\
\hline 3.69 & 3.43 & 0.067 & 1.054 & 3.56 \\
\hline
\end{tabular}

يوضح الجدول 6 أن الاتجاه العام لهذه العبارة بأنهم يكتبون في وسيلة التواصل الاجتماعي بلغة الإيموجي بكثرة (كثيرًا فقط) وذلك بثقة 95\% في القرار ، ولكي نتأكد من هذه النتيجة قمنا باختبارها: هل أن هناك كثيرون يكتبون في وسيلة التواصل الاجتماعي بلغة الإيموجي؟ فكانت القيمة الاحتمالية هي 0.014 وبالتالي معنوية الفرضية تنير إلى أن الرأي في هذا السؤال هو أن الكثير يكتبون في وسائل التواصل الاجتماعي بلغة الإيموجي.

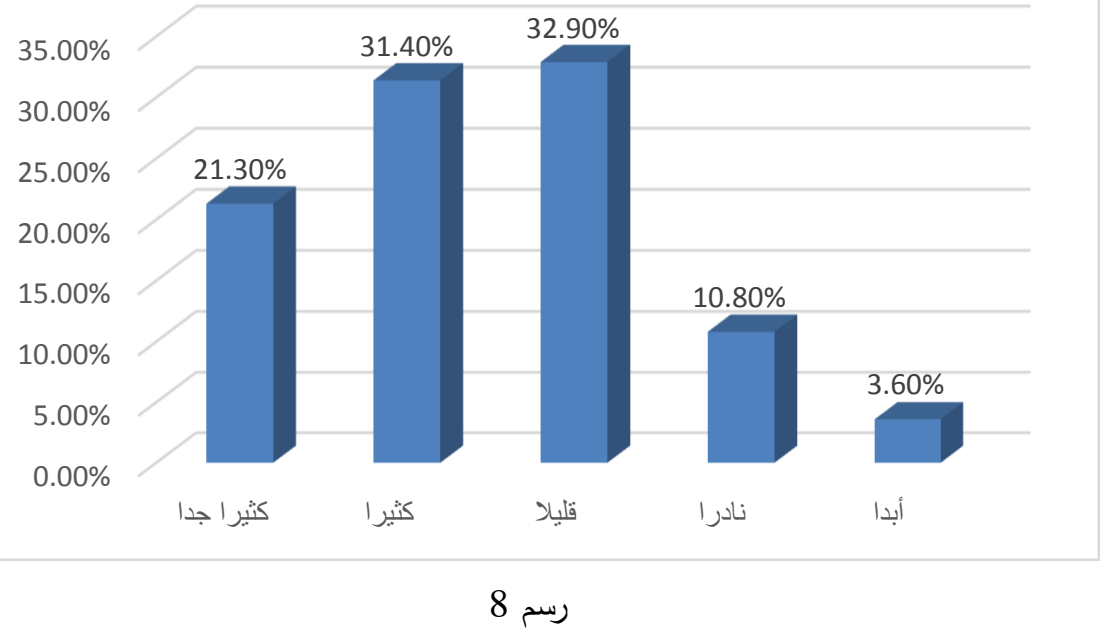


بع وسائل التواصل الاجتماعي تستخدم الإيموجي.

العبارة (5): ج)

\begin{tabular}{|c|c|c|c|c|}
\hline \multicolumn{2}{|c|}{ 95\% فترة ثقة } & \multirow{2}{*}{ الخطيأ } & \multirow{2}{*}{ الانحراف } & \multirow[b]{2}{*}{ المتوسط } \\
\hline الأعلى & الأدنى & & & \\
\hline 4.18 & 3.95 & 0.058 & 0.920 & 4.06 \\
\hline
\end{tabular}

يوضح الجدول 7 الاتجاه العام لهذه العبارة بأن جميع وسائل التواصل الاجنماعي تستخدم الإيموجي بكثزة (كثيرًا فقط) وذللك بثقة 95\% في القرار، ولكي نتأكد من هذه النتيجة قمنا باختبارها: هل أن جميع وسائل التواصل الاجتماعي تستخدم الإيموجي؟ فكانت القيمة الاحتمالية هي 0.000 وبالتالي معنوية الفرضية تشير إلى أن الرأي في هذا السؤال هو أن جميع وسائل التواصل الاجنماعي نستخدم الإيموجي كثيرًا. كما أننا نجد أن نسبة لا تقل عن 77.7 وهي نسبة معنوية (القيمة الاحتمالية 000) سبق واستفاد منها في مقرر دراسي

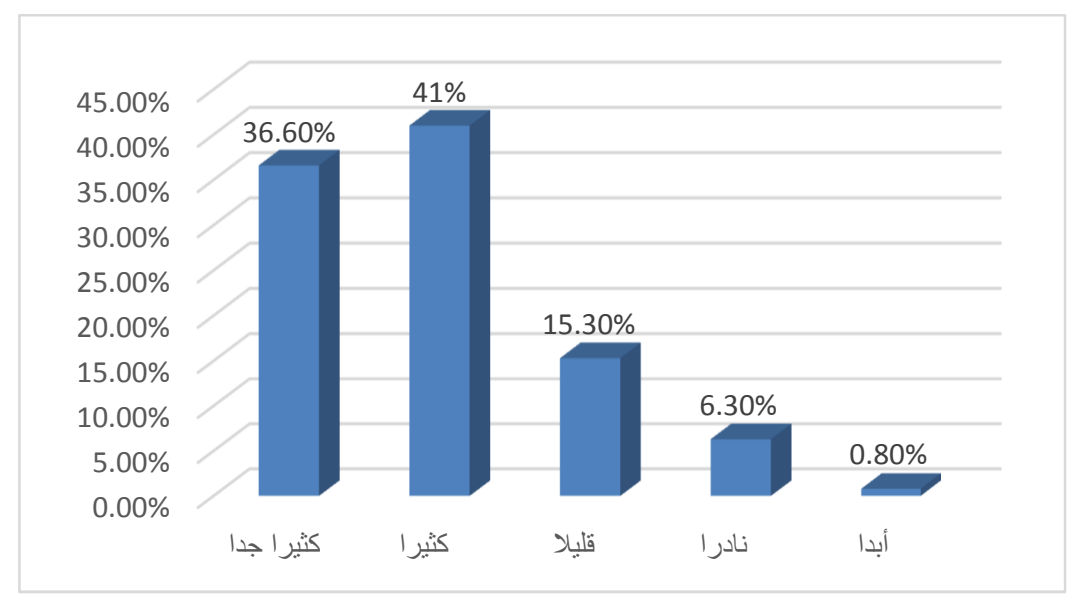

رسم 9 
دراسة المحور الثاني: لغة الإيموجي

العبارة 1: استخدم لغة الإيموجي

\begin{tabular}{|c|c|c|c|c|}
\hline \multicolumn{2}{|c|}{ 95\% فترة ثقة } & \multirow{2}{*}{ اليطاري } & \multirow{2}{*}{ الالنحراف } & \multirow[b]{2}{*}{ المتوسط } \\
\hline الأعلى & الأدنى & & & \\
\hline 3.9 & 3.66 & 0.063 & 0.625 & 3.78 \\
\hline
\end{tabular}

يوضح الجدول 8 الاتجاه العام لهذه العبارة بأنهم يستخدمون لغة الإيموجي "كثيرًا فقط" وذلك بثقة 95\% في القرار، ولكي نتأكد من هذه النتيجة قمنا باختبارها: هل أن هناك الكثير الذين يستخدمون لغة الإيموجي؟ فكانت القيمة الاحتمالية هي 0.000 وبالتالي معنوية الفرضية تشير إلى أن الرأي في هذا السؤال هو استخدام لغة الإيموجي كثيرًا. كما أننا نجد أن نسبة لا تقل عن 59.5\% وهي نسبة معنوية (القيمة الاحتمالية 000) تستخدم لغة الإيموجي بكثرة.

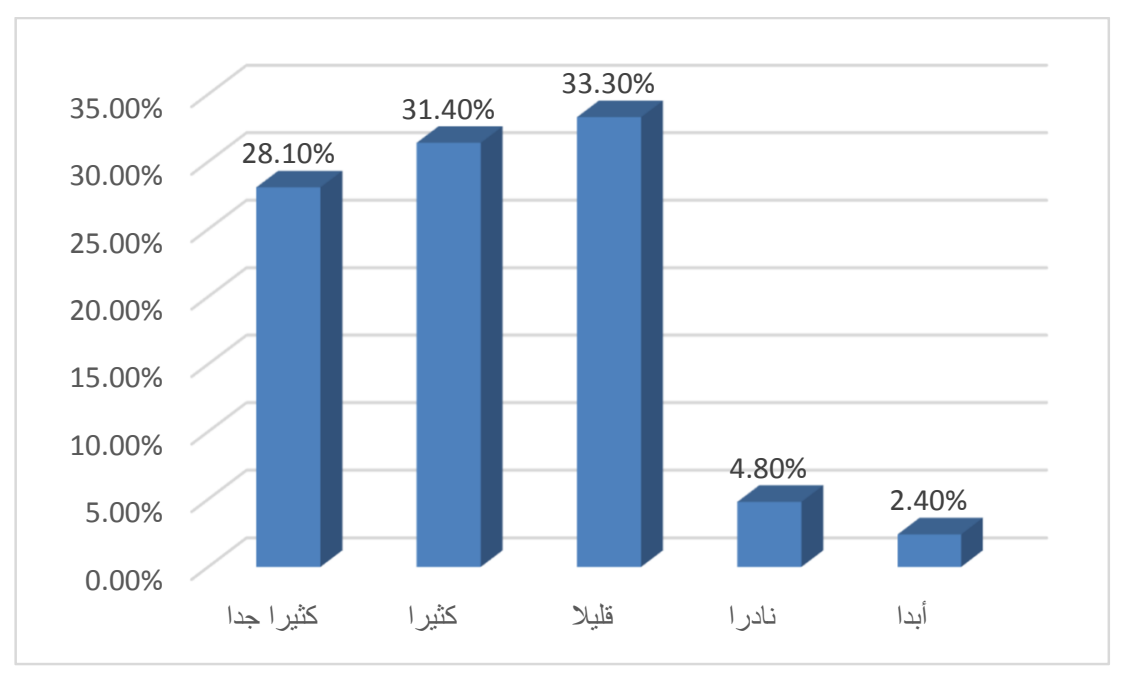

رسم 10 
العبارة 2: تعابير الإيموجي لغة جديدة للحوار :

\begin{tabular}{|c|c|c|c|c|}
\hline \multicolumn{2}{|c|}{ 95\% فترة ثقة } & \multirow{2}{*}{ الخعياري } & \multirow{2}{*}{ الالمعراف } & \multirow[b]{2}{*}{ المتوسط } \\
\hline الأعلى & الأدنى & & & \\
\hline 3.97 & 3.72 & 0.064 & 1.012 & 3.85 \\
\hline
\end{tabular}

يوضح الجدول9 الاتجاه العام لهذه العبارة بأن الكثير يعلمون أن تعابير لغة الإيموجي هي لغة جديدة للحوار "كثيرًا فقط" وذلك بثقة 95\% في القرار، ولكي نتأكد من هذه النتيجة قمنا باختبارها: هل أن هناك الكثير مِسَّن يعلمون أن تعابير لغة الإيموجي لغة جديدة للحوار؟ فكانت القيمة الاحتمالية هي 0.000 وبالتالي معنوية الفرضية أن الرأي في هذا السؤال هو أن مَن يعلمون أن تعابير لغة الإيموجي لغة جديدة للحوار كثيرون. كما أننا نجد أن نسبة لا تقل عن 69.5\% وهي نسبة معنوية (القيمة الاحتمالية 0.000) تعلم أن تعابير لغة الإيموجي لغة جديدة للحوار كثير ·

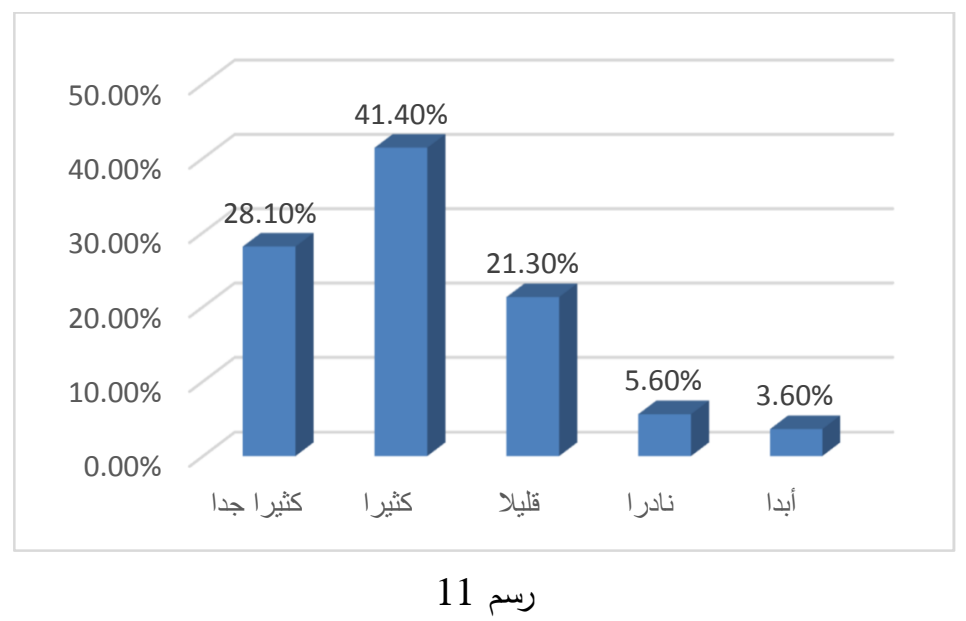


العبارة3: نحتاج رموز إيموجي عربية جديدة تعبر عن بيئتنا و حضارتنا و ثقافتنا

\begin{tabular}{|c|c|c|c|c|}
\hline \multicolumn{2}{|c|}{ 95\% فترة ثقة } & \multirow{2}{*}{ المعياري } & \multirow{2}{*}{ المعياري } & \multirow[b]{2}{*}{ المتوسط } \\
\hline الأعلى الحد & الأدنى & & & \\
\hline 4.95 & 3.65 & 0.078 & 1.225 & 3.80 \\
\hline
\end{tabular}

يوضح الجدول 10 أن الاتجاه العام لهذه العبارة يوضح أنهم في حاجة لرموز إيموجي عربية جديدة تعبر عن بيئتا و حضارتتا و ثقافتتا بكثرة "كثيرًا فقط" وذلك بثقة 95\% في القرار ولكي نتأكد من هذه النتيجة قمنا باختبار هل أن هناك كثيرًا في حاجة لرموز إيموجي عربية جديدة تعبر عن بيئتنا و حضارتتا و ثقافتتا؟ فكانت القيمة الاحتمالية هي 0.000 وبالتالي معنوية الفرضية أن الرأي هنا: أن الكثير في حاجة لرموز إيموجي عربية جديدة تعبر عن بيئتنا وحضارتتا وثقافتتا. كما أننا نجد أن النسبة لا تقل عن 62.3\% وهي نسبة معنوية (القيمة الاحتمالية 000) - (0.00).

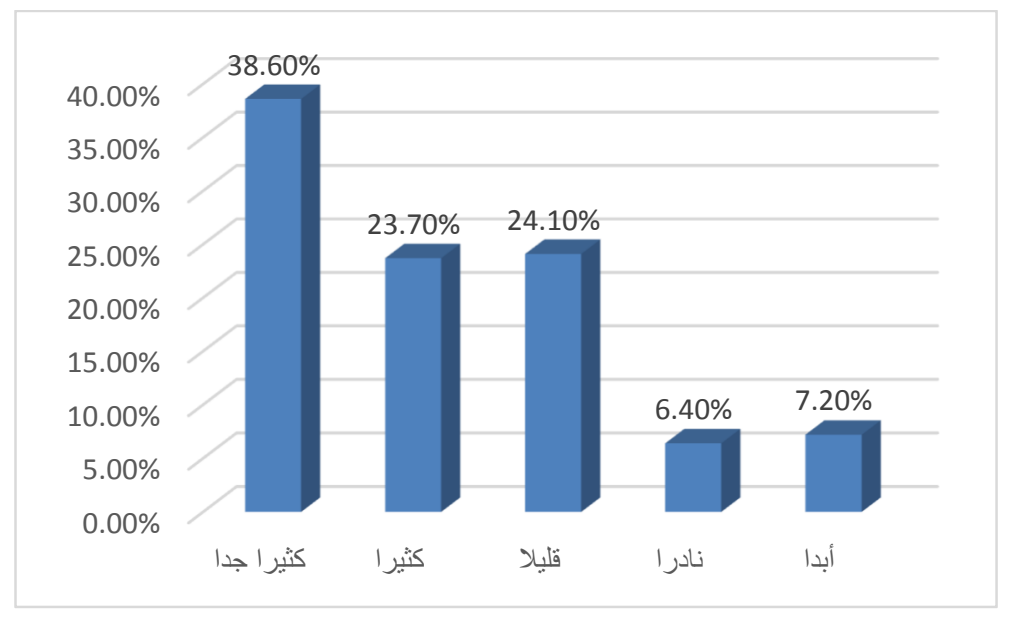

رسم 12 
العبارة4: يتكلم العالم الإيموجي كلغة موحدة بلا حروف ولا قواعد

\begin{tabular}{|c|c|c|c|c|}
\hline \multicolumn{2}{|c|}{ 95\% فترة ثقة } & \multirow{2}{*}{ الخطأ } & \multirow{2}{*}{ الانحراف } & \multirow[b]{2}{*}{ المتوسط } \\
\hline الأعلى & الألدى & & & \\
\hline 4.03 & 3.77 & 0.066 & 1.039 & 3.9 \\
\hline
\end{tabular}

يوضح الجدول 11 أن الاتجاه العام لهذه العبارة بأنهم يعلمون أنه يتكلم العالم الإيموجي كلغة موحدة بلا حروف ولا قواعد بكثرة "كثثرًا فقط" وذلك بثقة 95\% في القرار ولكي نتأكد من هذه النتيجة قمنا باختبار العبارة، فكانت القيمة الاحتمالية هي 0.000 وبالتالي معنوية الفرضية أن الرأي: أنهم يعلمون أنه العالم يتكلم الإيموجي كلغة موحدة بلا حروف ولا قواعد "بكثرة كثيرًا". كما أننا نجد أن نسبة لا تقل عن 67.2\% وهي نسبة معنوية (القيمة الاحتمالية 0.014) تعلم أن العالم يتكلم الإيموجي كلغة موحدة بلا حروف ولا قواعد "بكثرة".

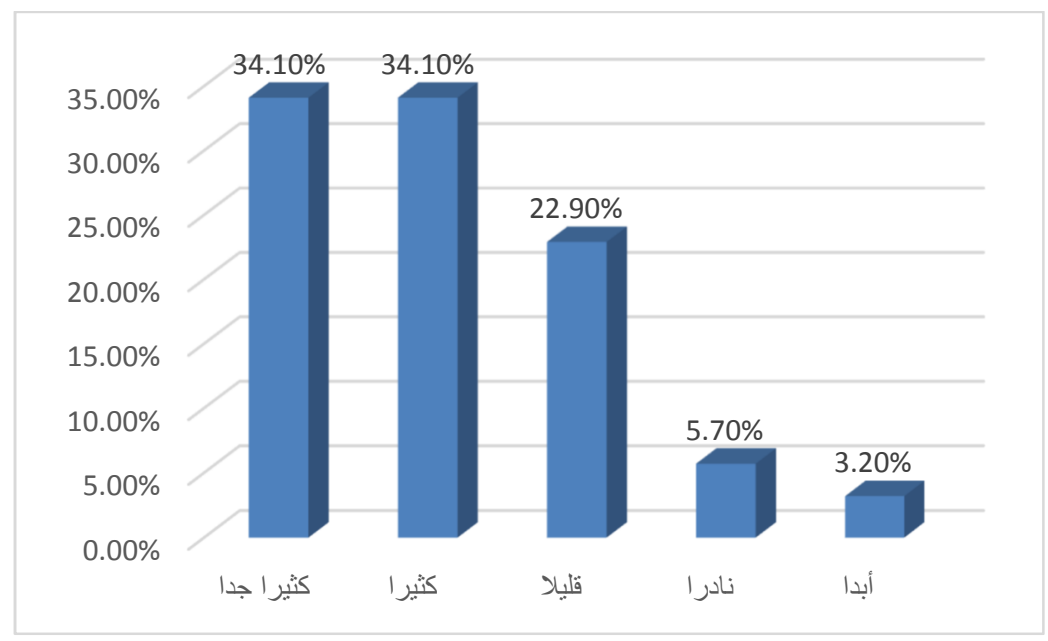

رسم 13 
العبارة5: تعبر الإيموجي عن معان متعددة كما يحصل في استخدام الكلمات

\begin{tabular}{|c|c|c|c|c|}
\hline \multicolumn{2}{|c|}{ 95\% فترة ثقة } & \multirow{2}{*}{ المعياري } & \multirow{2}{*}{ الانحراف } & \multirow[b]{2}{*}{ المتوسط } \\
\hline الأعلى & الأدنى & & & \\
\hline 4.23 & 4.00 & 0.058 & 0.919 & 4.12 \\
\hline
\end{tabular}

جدول 12

يوضح الجدول 12 أن الاتجاه العام لهذه العبارة بأن المستخدمين يعلمون أن الإيموجي تعبر عن معان متعددة كما يحصل في استخدام الكلمات بكثرة (كثيرًا فقط) وذلك بثقة 95\% في القرار ولكي نتأكد من هذه النتيجة قمنا باختبارها، فكانت القيمة الاحتمالية هي 0.000 وبالتالي معنوية الفرضية أن الرأي في هذا السؤال هو أن المستخدمين يعلمون أنها تعبر عن معان متعددة كما يحصل في استخدام الكلمات "بكثرة". كما أننا نجد أن نسبة لا تقل عن 77.9 وهي نسبة معنوية (القيمة الاحتمالية 0000) تعلم أنها تعبر عن معان متعددة كما

يحصل في استخدام الكلمات "بكثرة".

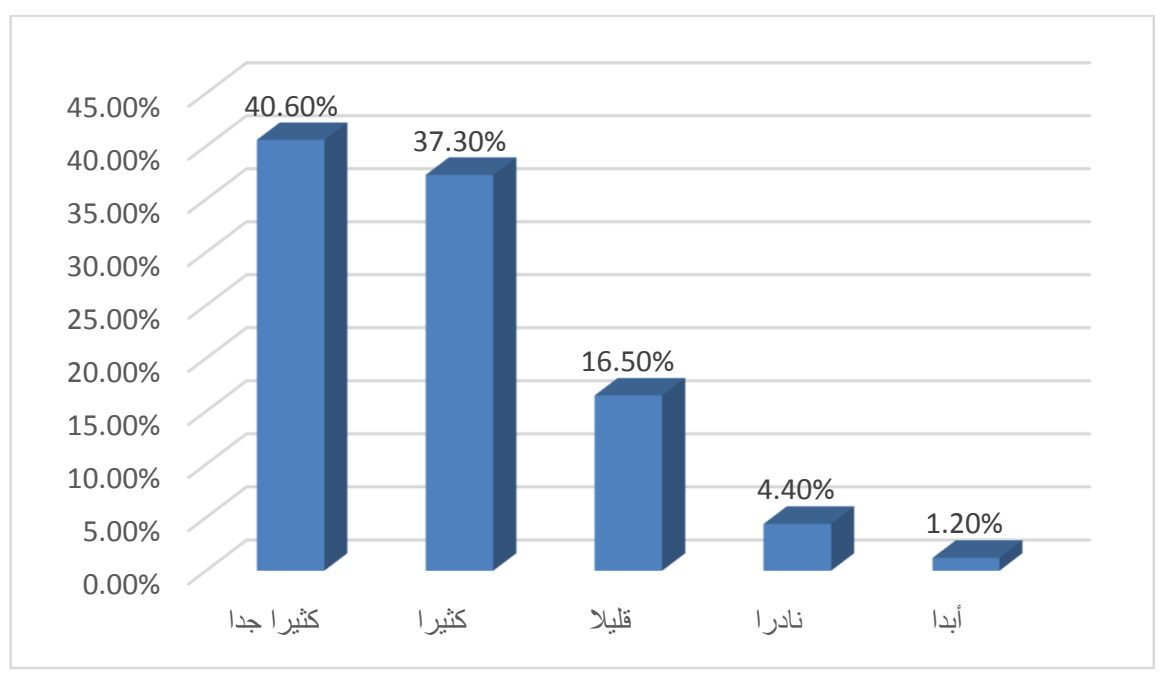

رسم 14 
العبارة6: تؤئر لغة الإيموجي سلبًا على اللغة بشكل عام

\begin{tabular}{|c|c|c|c|c|}
\hline \multicolumn{2}{|c|}{ 95\% فترة ثقة } & \multirow{2}{*}{ المعياري } & \multirow{2}{*}{ الانحراف } & \multirow{2}{*}{ المنوسط } \\
\hline الحد الأعلى & الحد الأدنى & & & \\
\hline 3.39 & 3.08 & 0.077 & 1.219 & 3.23 \\
\hline
\end{tabular}

جدول 13

من الجدول 13 يتضح أن الاتجاه العام لهذه العبارة يوضح أن المستخدمين الذين يعتقدون أن لغة الايموجي تؤثر سلبًا على اللغة بشكل عام قليلًا ولكن لا تتجه إلى الندرة وذلك بثقة 95\% في القرار ولكي نتأكد من هذه النتيجة قمنا باختبار هل أن هناك القليل من المستخدمين الذين يعتقدون أن لغة الإيموجي تؤثر سلبًا على اللغة بشكل عام؟ فكانت القيمة الاحتمالية هي 0.000 وبالتالي معنوية الفرضية أن الرأي في هذا السؤال هو أن المستخدمين الذين يعتقدون أن لغة الإيموجي تؤئز سلبًا على اللغة بشكل عام قليلًا ولكن لا تتجه إلى الندرة. كما أننا نجد أن نسبة لا تقل عن 33.3\% وهي نسبة معنوية (القيمة الاحتمالية 0.000) من المستخدمين الذين يعتقدون أن لغة الإيموجي تؤثر سلبًا على اللغة بشكل عام قليلًا ولكن لا تتجه إلى الندرة. كما أن النسبة للكثرة هي 31\% ولكنها غير معنوية وكذلك نسبة الندرة 25.7\% ولكنها أيضًا غير معنوية لذلك لا يمكن الاعتماد عليهما.

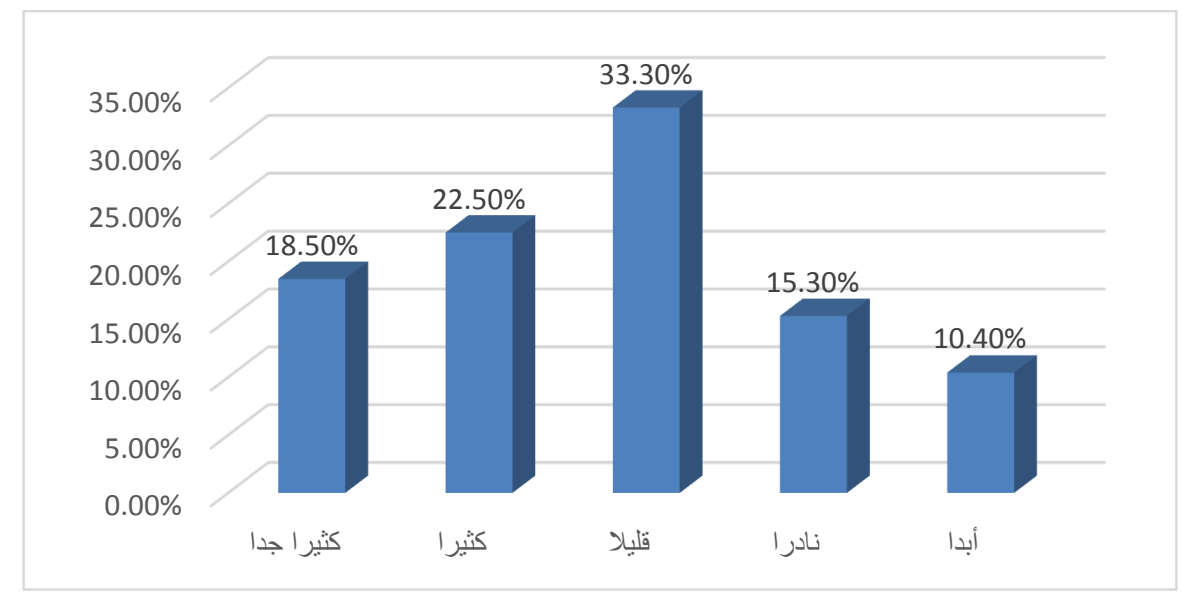

رسم 15 
العبارة (7): تساعد لغة الإيموجي على إيصال الرسالة بطريقة أسرع.

\begin{tabular}{|c|c|c|c|c|}
\hline \multicolumn{2}{|c|}{ 95\% فترة نقة } & \multirow{2}{*}{ المعياري } & \multirow{2}{*}{ الانحراف } & \multirow[b]{2}{*}{ المنوسط } \\
\hline الأعلى & الأدنى & & & \\
\hline 4.20 & 3.96 & 0.061 & 0.970 & 4.08 \\
\hline
\end{tabular}

من الجدول 14 يتضح أن الاتجاه العام لهذه العبارة يوضح أن المستخدمين يعلمون أنه تساعد لغة الإيموجي على إيصال الرسالة بطريقة أسرع (كثثرون فقط) وذلك بثقة 95\% في القرار ولكي نتأكد من هذه النتيجة قمنا باختبار هل أن هناك الكثثر الذين يعلمون أنه لغة الإيموجي تساعد على إيصال الرسالة بطريقة أسرع؟ فكانت القيمة الاحتمالية هي 0.011 وبالتالي معنوية الفرضية أن الرأي في هذا السؤال هو أن المستخدمين لـ: تساعد لغة الإيموجي على إيصال الرسالة بطريقة أسرع "كثيرون". كما أننا نجد أن نسبة لا تقل عن 85.9\% وهي نسبة معنوية (القيمة الاحتمالية 0.000) تساعد لغة الإيموجي على إيصال الرسالة بطريقة أسرع

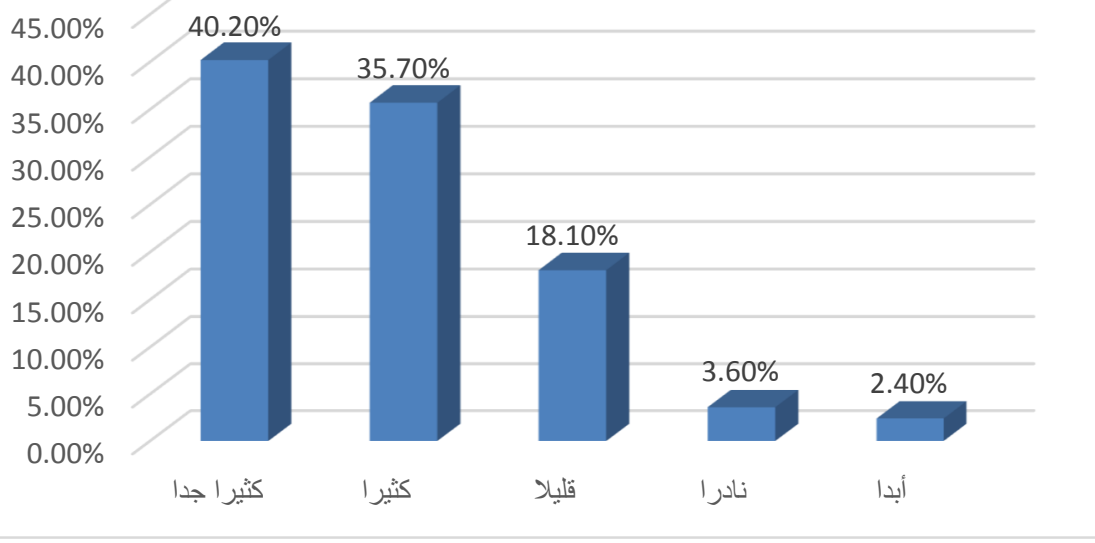

رسم 16 
دراسة المحور الثالث : الترجمة العبارة (1): يمكن أن تحل الإيموجي بلاًا عن الترجمة.

\begin{tabular}{|c|c|c|c|c|}
\hline \multicolumn{2}{|c|}{ 95\% فترة نقة } & & الآنحراف & \\
\hline الحد الأعلى & الحد الأدنى & المعياري & المعياري & \\
\hline 2.63 & 2.31 & 0.081 & 1.283 & 2.47 \\
\hline
\end{tabular}

من الجدول 15 يتضح أن الاتجاه العام لهذه العبارة يوضح أن من بعتقدون أن تحل الإيموجي بدلًا عن الترجمة "نادرون" وذلك بتقة 95\% في القرار ولكي نتأكد من هذه النتيجة قمنا باختبار هل أن هناك من يعتقدون أن تحل الإيموجي بدلً عن الترجمة "نادرون "؟ فكانت القيمة الاحتمالية هي 0.000 وبالتالي معنوية الفرضية هنالك نسبة نادرة من المجتمع تعتقد أن تحل لغة الإيموجي محل الترجمة.

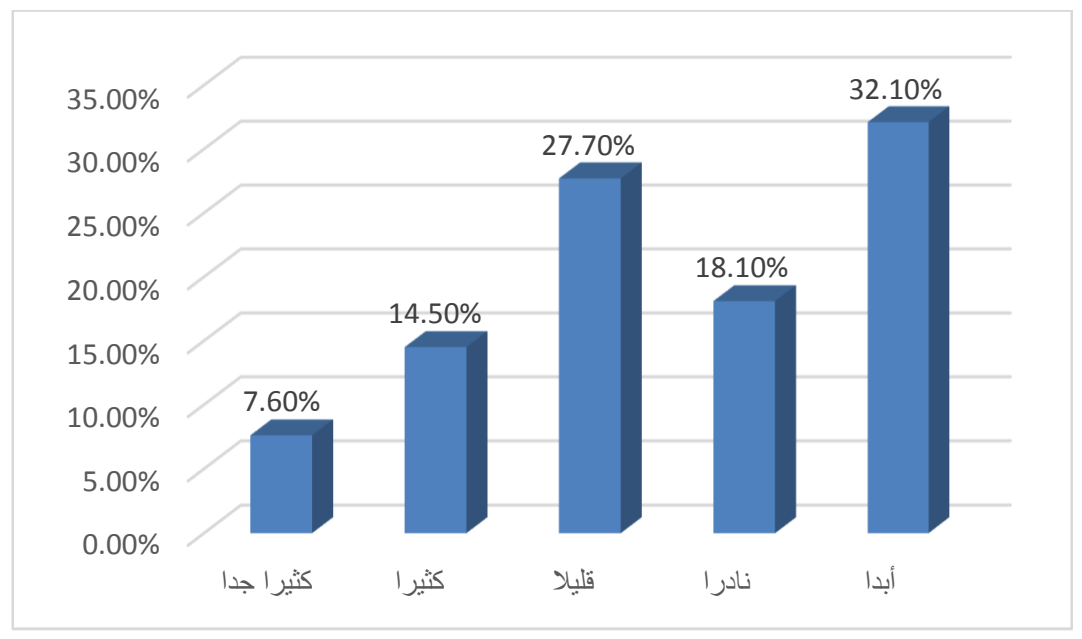

رسم 17

العبارة (2): يعيق الترجمة الرقمية تعبيرها عن المشاعر.

\begin{tabular}{|c|c|c|c|c|}
\hline \multicolumn{2}{|c|}{ 95\% فترة ثقة } & \multirow{2}{*}{ الخعياري } & \multirow{2}{*}{ الالمراف } & \multirow{2}{*}{ المتوسط } \\
\hline الحد الأعلى & الحد الأدنى & & & \\
\hline 3.54 & 3.27 & 1.093 & 1.012 & 3.41 \\
\hline
\end{tabular}


من الجدول 16 يتضح أن الاتجاه العام لهذه العبارة يوضح أن مَن يعلمون أن الترجمة الرقمية تعيق التعبير عن المشاعر قليلون وذلك بثقة 95\% في القرار ولكي نتأكد من هذه النتيجة قمنا باختبار هل أن هناك الكثيرون الذين يعلمون أن تعابير لغة الإيموجي لغة جديدة للحوار؟

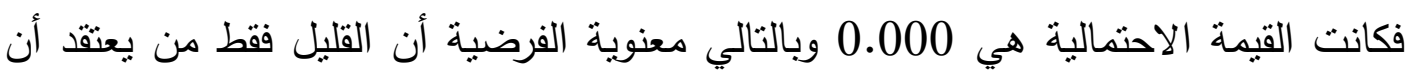
الثرجمة الرقمية تعيق التعبير عن المشاعر.

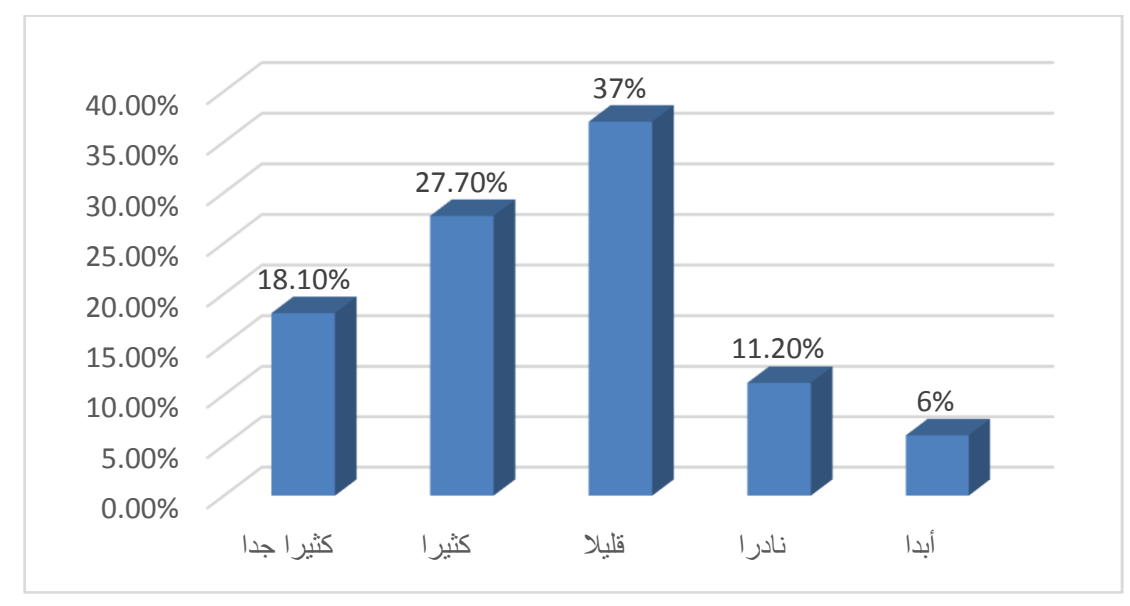

رسم 18

العبارة (3): يُعد تأثير لغة الإيموجي سلبيًّا على الكتابة.

\begin{tabular}{|c|c|c|c|c|}
\hline \multicolumn{2}{|c|}{ 95\% فترة ثقة } & \multirow{2}{*}{ المعياري } & \multirow{2}{*}{ الانحراف } & \multirow{2}{*}{ المنوسط } \\
\hline الحد الأعلى & الحد الأدنى & & & \\
\hline 3.39 & 3.08 & 0.079 & 1.252 & 3.23 \\
\hline
\end{tabular}

جدول 17

من الجدول 17 يتضح أن الاتجاه العام لهذه العبارة يوضح أنهم من يعد تأثير لغة الإيموجي سلبيًّا على الكتابة قليلون وذللك بثقة 95\% في القرار ولكي نتأكد من هذه النتيجة قمنا باختبار هل القليل هم الذين بعدون تأثير لغة الايموجي سلبيًّا على الكتابة؟ فكانت القيمة الاحتمالية

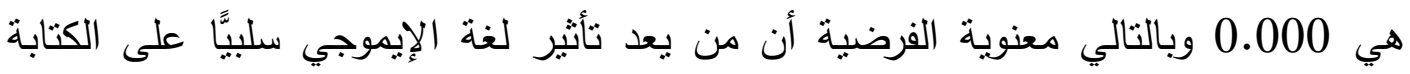
قليلون. 


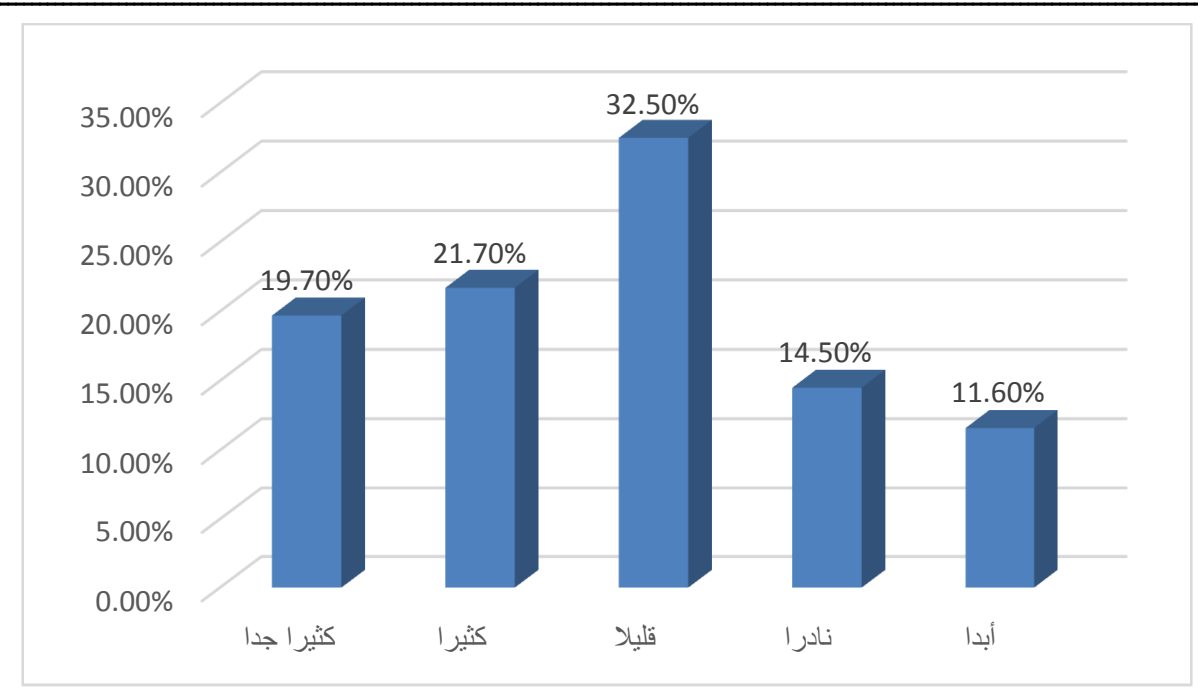

رسم 19

العبارة (4): استخدم لغة الإيموجي في التعبير بها مع الآخر الذي لا نجيد لغته بدلاً من

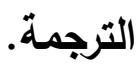

\begin{tabular}{|c|c|c|c|c|}
\hline \multicolumn{2}{|c|}{ 95\% فترة ثقة } & \multirow{2}{*}{ الخطيأ } & \multirow{2}{*}{ الالحراف } & \multirow[b]{2}{*}{ المتوسط } \\
\hline الأعلى الحد & الأدنى & & & \\
\hline 3.27 & 2.95 & 0.08 & 1.286 & 3.11 \\
\hline
\end{tabular}

من الجدول 18 يتضح أن الاتجاه العام لهذه العبارة يوضح أنهم نادرًا ما يستخدمون لغة الإيموجي في التعبير بها مع الآخر الذي لا يجيدون لغته بدلاً من التزجمة وذلك بثقة 95\%

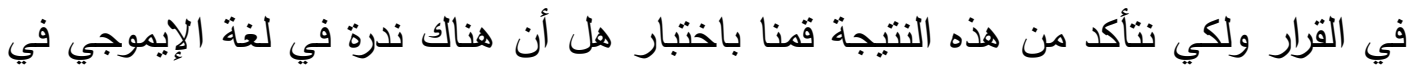

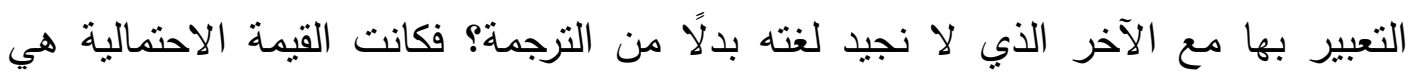

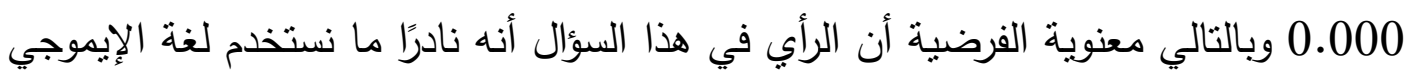
في التعبير بها مع الآخر الذي لا نجيد لغته بدلاً من الترجمة. 


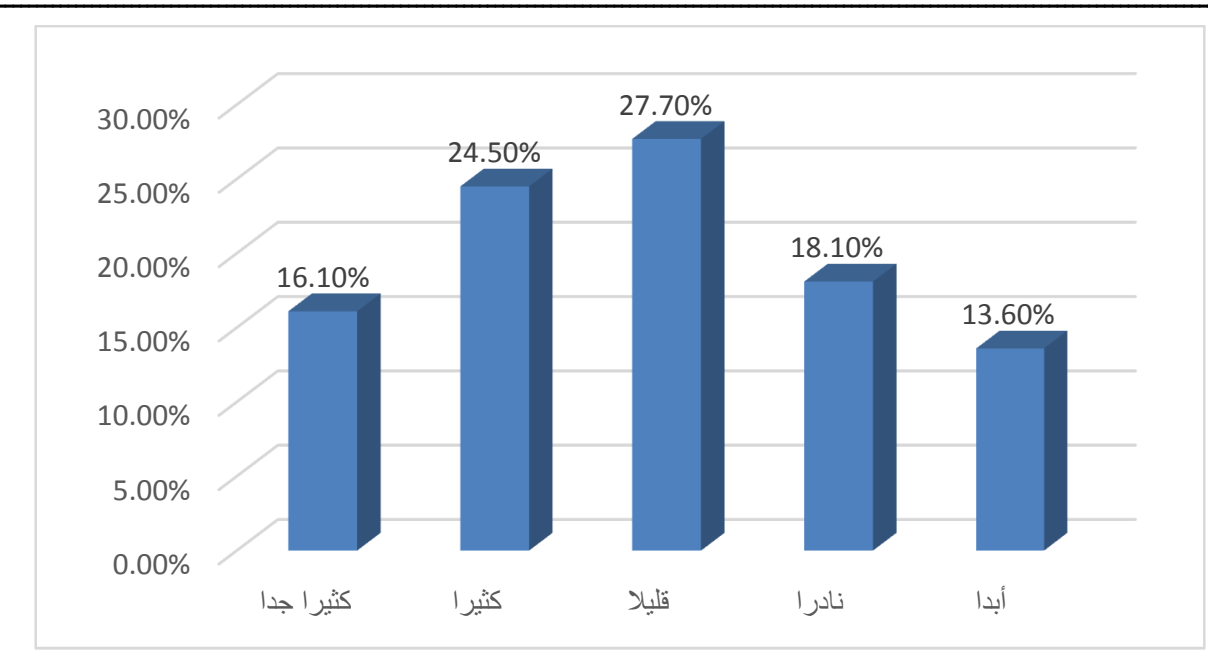

رسم 20

العبارة (5): اعرف تطبيقات تحوّل النصوص/الكلمات إلى تعابير إيموجي •

\begin{tabular}{|c|c|c|c|c|}
\hline \multicolumn{2}{|c|}{ 95\% فترة ثقة } & \multirow{2}{*}{ المعياري } & \multirow[b]{2}{*}{ المعياري } & \multirow[b]{2}{*}{ المنوسط } \\
\hline الأعلى & الأدنى & & & \\
\hline 2.02 & 1.72 & 0.076 & 1.205 & 1.87 \\
\hline
\end{tabular}

جدول 19

من الجدول 19 يتضح أن الاتجاه العام لهذه العبارة يوضح أن "نادرًا أو أبدًا " ما يعرف المستخدمون أن هنالك تطبيقات تحوّل النصوص/الكلمات إلى تعابير إيموجي وذللك بثقة 95\% في القرار ولكي نتأكد من هذه النتيجة قمنا باختبار هل أن قليلً ما يعرف المستخدمون أن هناك تطبيقات تحوّل النصوص/الكلمات إلى تعابير إيموجي؟ فكانت القيمة الاحتمالية هي 0.175 وبالتالي عدم معنوية الفرضية بينما إذا اختبرنا أنه ليس هناك أحد يعرف أن هناك تطبيقات تحوّل النصوص/الكلمات إلى تعابير إيموجي؟ فكانت القيمة الاحتمالية هي 0.000 وبالتالي الفرضية الرأي في هذا السؤال هو أن ليس هناك أحد يعرف من المستخدمين أن هناك تطبيقات تحوّل النصوص/الكلمات إلى تعابير إيموجي. 


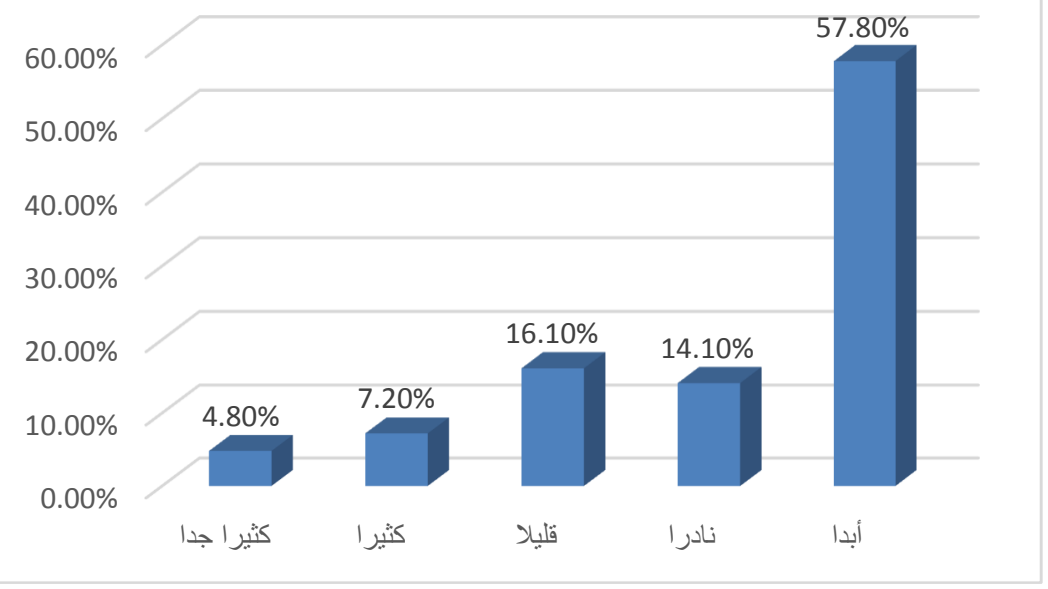

رسم 21

العبارة (6): تخدم الإيموجي الترجمة من خلال تحويل الكلمات إلى رموز إيموجي عبر تطبيقات.

\begin{tabular}{|c|c|c|c|c|}
\hline \multicolumn{2}{|c|}{ 95\% فترة نقة } & \multirow{2}{*}{ المعياري } & \multirow{2}{*}{ الانحراف } & \multirow[b]{2}{*}{ المتوسط } \\
\hline الأعلى الحد & الأدنى & & & \\
\hline 2.9 & 2.59 & 0.078 & 1.227 & 2.74 \\
\hline
\end{tabular}

من الجدول 20 يتضح أن الاتجاه العام لهذه العبارة يوضح أن المستخدمين الذين يعتقدون أن تخدم الإيموجي الترجمة من خلا تحويل الكلمات إلى رموز إيموجي عبر تطبيقات قلبلون ولكن لا تتجه إلى الندرة وذلك بثقة 95\% في القرار ولكي نتأكد من هذه النتيجة قمنا باختبار هل أن هناك قليلٌ من المستخدمين الذين يعتقدون أن تخدم الإيموجي الترجمة من خلال تحويل الكلمات إلى رموز إيموجي عبر تطبيقات؟ فكانت القيمة الاحتمالية هي 0.044 وبالتالي معنوية الفرضية أن الرأي في هذا السؤال هو أنه قليلٌ من يعتقد أن الإيموجي تخدم الترجمة من خلال تحويل الكلمات إلى رموز إيموجي عبر تطبيقات. 


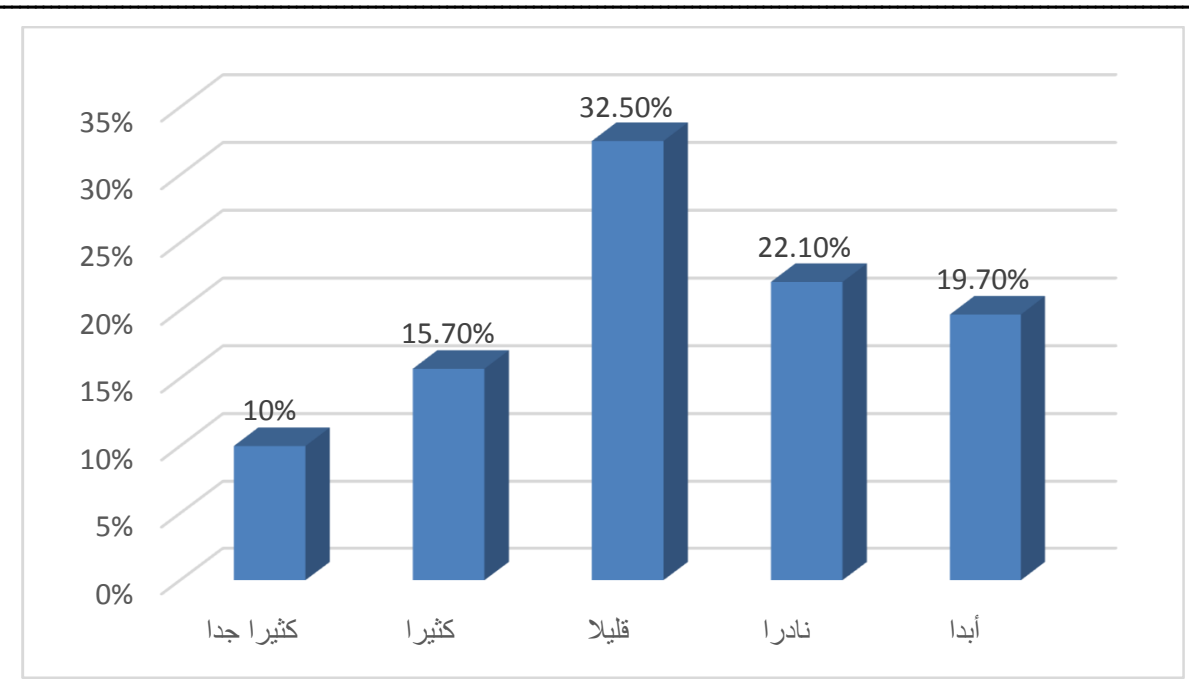

رسم 22

العبارة (7): أوئيد فكرة تعلم الترجمة باستخدام تعابير الإيموجي.

\begin{tabular}{|c|c|c|c|c|}
\hline \multicolumn{2}{|c|}{ 95\% فترة ثقة } & \multirow{2}{*}{ المعياري } & \multirow{2}{*}{ الالنحراف } & \multirow{2}{*}{ المتوسط } \\
\hline الحد الأعلى & الحد الأدنى & & & \\
\hline 2.93 & 2.61 & 0.082 & 1.293 & 2.77 \\
\hline
\end{tabular}

من الجدول 21 يتضح أن الاتجاه العام لهذه العبارة يوضح أن المستخدمين قليل منهم من يؤيد فكرة تعلم الترجمة باستخدام تعابير الإيموجي وذلك بثقة 95\% في القرار ولكي نتأكد من هذه النتيجة قمنا باختبار هل المستخدمون قليل منهم من يؤيد فكرة تعلم الترجمة باستخدام تعابير الإيموجي؟ فكانت القيمة الاحتمالية هي 0.026 وبالتالي معنوية الفرضية أن الرأي في هذا السؤال هو أن المستخدمين قليل منهم من يؤيد فكرة تعلم الترجمة باستخدام تعابير الإيموجي. 


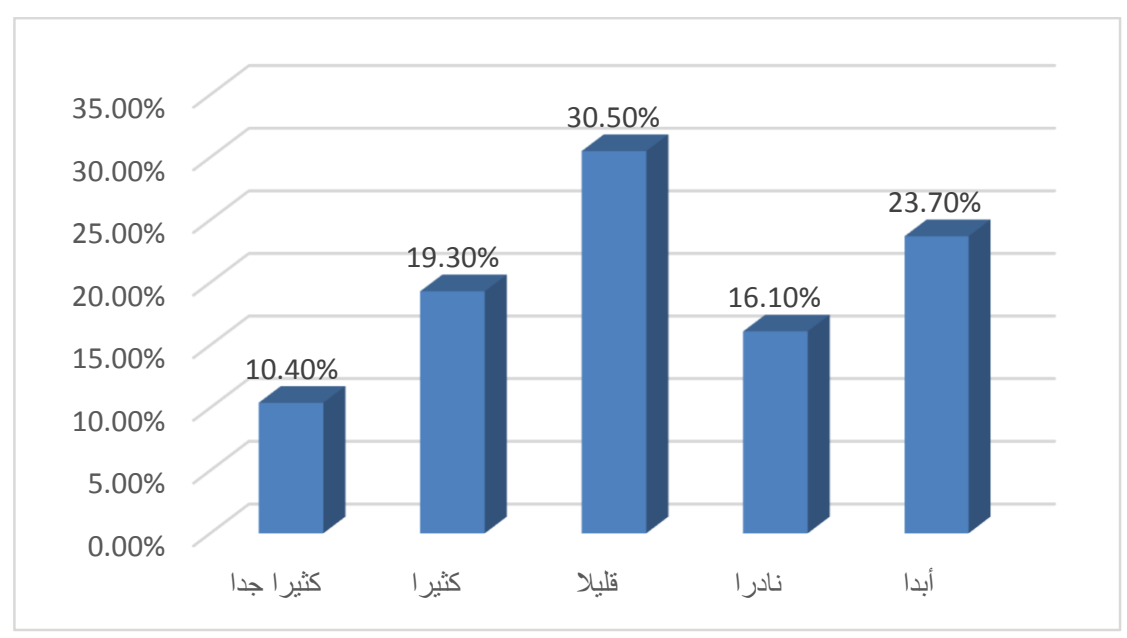

وعليه نوضح النتائج السابقة ردود عينة الدراسة على بعض تساؤلات السابقة البحث :

أن لغةَ تعابير "الإيموجي" دارجة لدى مجتمع الدراسة، وبالتالي فأنهم يمنلون اقرانهم لدى المجتمع العربي والعالمي جيل رقمي يمكن أن يتواصل ويتفاهم عبر وسائل التواصل الاجتماعي في سياقات معينة دون الحاجة لأدوات الترجمة التقليدية. وبأنه يتجه جيل الثباب الرقمي نحو التفاعل مع التقنية لتكوين لغة رمزية تعبيرية تواصلية موحدة مستمدة من ثقافات متعددة تعمل جنبًا إلى جنب مع اللغة الطبيعية لتكون وسيلة سهلة مساندة في التواصل العام دون أن تحل بشكل كلي محل اللغة الطبيعية خصوصًا في سياقاتها البحنية والتعليمية، إلخ... - مولقد كانت الإجابات على عبارة "استخلم وبائل التواصل الاجتماعي"، الاتجاه العام لهذه العبارة استخدام وسائل التواصل الاجتماعي بـ"كثيرٍ جداً" وذلك بثقة 95 في القرار (انظر الرسم 5). وعبارة : أكتب في وسيلة التواصل الاجتماعي بلغة الإيموجي، نجد أن الاتجاه العام لهذه العبارة بأنهم يكتبون في وسيلة التواصل الاجتماعي بلغة الإيموجي "بكثرة" بثقة 95\% في القرار (أنظر الرسم 8)، بينما عبارة تؤثئر لغة الإيموجي سلبًا على اللغة بشكل عام، أن الاتجاه العام 
لهذه العبارة يوضح أن المستخدمين الذين بعتقدون أن لغة الإيموجي تؤثر سلبًا

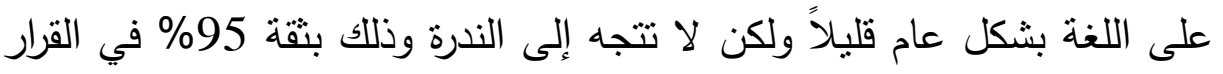
(أنظر الرسم 15). وللتأكد من هذا الجانب يتضح أن الاتجاه العام لتأثنير متل

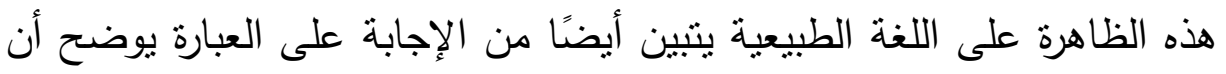

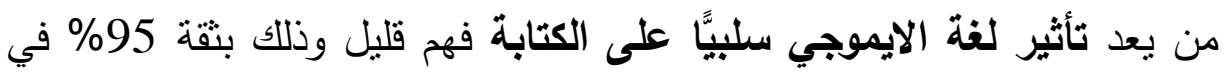
القرار ، أنظر للرسم 19. وهو بذلك يشير بوعيه لقوة نظام اللغة الطبيعية

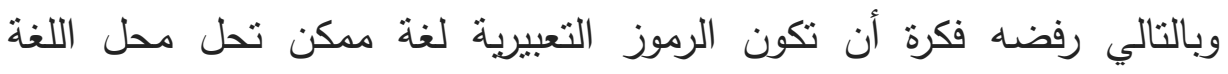
الطبيعية. ويؤكد ثلك النتيجة ما ذهب إليه بيير هالثيه: "ل يحل الرمز العاطفي

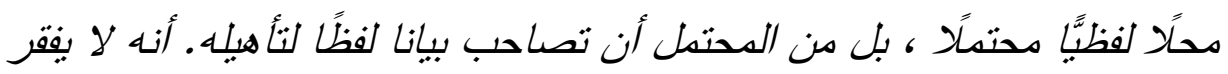

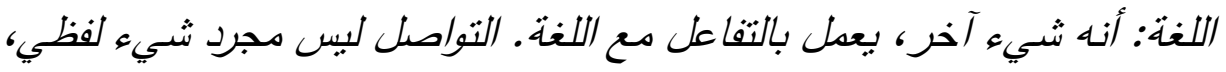
أنه تفاعل بين اللغة والإبياءة والثقليد". (Pierre Halté)

وفي محور التزجمة: يمكن أن تحل الإيموجي بدلًا عن الترجمة. يتضح أن الاتجاه العام لهذه

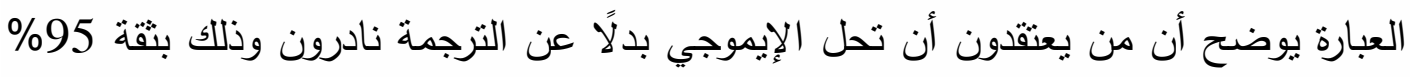

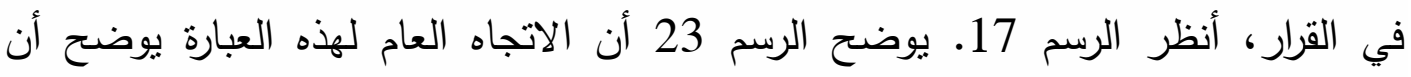
المستخدمين قليل منهم من يؤيد فكرة تعلم الترجمة باستخدام تعابير الإيموجي وذلك بثقة 95\% في القرار . استخدم لغة الإيموجي في التعبير بها مع الآخر الأي لا نجيد لغته بدلاً

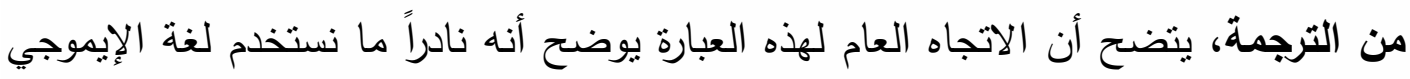

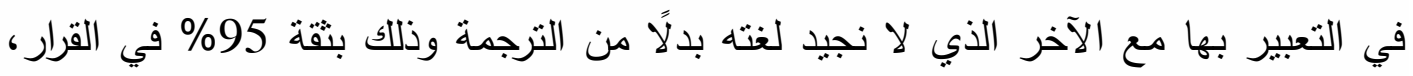
رسم 21, تخدم الإيموجي الترجمة من خلا تحويل الكلمات إلى رموز إيموجي عبر تطبيقات، الرسم 22 يوضح أن الاتجاه العام لهذه العبارة بأن الدستخدمين الذين يعتقدون أن

${ }^{36}$ https://crem.univ-lorraine.fr/halte-pierre 
تخدم الإيموجي الترجمة من خلال تحويل الكلمات إلى رموز إيموجي عبر تطبيقات قليلون ولكن لا تتجه إلى الندرة وذللك بثقة 95\% في القرار .

يمكن أن نوجز بأن معظم نتائج عبارات الدراسة، أيضًا هو ما ذهب إليه بعض الباحثين بأن الرموز التعبيرة عبارة عن أداة مساندة للغة يتفاعل معها الجيل الرقمي الحالي وستتلاشى مع بروز ظاهرة أخرى مستقبلًا (أنظر : كتاب مارسيل دينسي (Marcel Danesi, 2016) ويستتد كتابه على المبادئ الأساسية السيميائية للتحليل)، وذلك يقوي فرضيتتا السابقة بأن الثباب يتفاعل من وقت لآخر مع الوسائل المتاحة له في حينه لتوظيفها كأداة مساندة للتواصل لهذا السبب يقول اللغويون أن اللغة "متعدة الوسائط"، وبالتالي لا تُعد كونها وسيلة تواصل تفاعلية من خلال وسائل التواصل الاجتماعي ما تلبث أن تختفي لتحل محلها وسيلة بشكل آخر مع

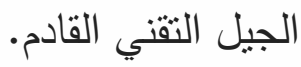




\section{7. خاتمة وتوصيات:}

اللغةُ كائنٌ حيٌّ تتعرض لكافة العوامل المؤثرة سلبًا أم ايجابًا من تطور وانتشار أو اندثار ، وكذلك هي خاضعة لتقلبات الزمن نتيجة للنطورات والمتغيرات والمستجدات وبالتالي فإن نمط حياتتا التواصلية المعاصرة منل الجوال والثنات والتطبيقات، إلخ...فرضت علينا منل هذه الوسائل. نشهد في الواقع استخدامًا ضخمًا للرموز التعبيرية في الرسائل النصية القصيرة والتغربدات والرسائل الأخرى على الثبكات الاجتماعية، وقد تكون ولادة شكل جديد من اللغة غير الرسمية التي تستخدم الإيماءات والأشكال ونبرة الصوت للتواصل بسرعة وسهولة. وعطفًا على نتائج استبانة الدراسة نستتنج بأن التواصل من خلال وسائل التواصل الاجتماعي من خلال وسيلة الرموز التعبيرية "الإيموجي" يفضي لبعض المعطيات: - - دفعت وسائل التواصل الجديدة الثباب بكافة جنسياته للاختصار عندما حددت رسائلها بحروف محددة منل التغريدة .

- فرضت وسائل التواصل الاجتماعي لغةً مكتوبةً جديدةً وبتعابير مستحدثة. - - تستخدم عدد من شركات الطيران والفنادق والمسنتفيات وغيرها التقييم من خلال رموز الإيموجي (الوجه:) وبهذه الطريقة لا تأخذ من الثخص أكثر من ثانية للضغط على الزر في مقعد المسافر مثنا عن مدى رضاه عن الرحلة من خلال اختيار الوجه المناسب، فضلًا عن وضوح المعنى دون الحاجة لمعرفة لغة أو ترجمة.

- يمكن استخدام لغة الإيموجي في المحادثات العامة البسيطة وفي الإعلان والدعاية وفي سرد قصص صغيرة ودليل استخدام لبعض الأجهزة، إلخ... - يمكن استخدام بعض الرموز للمراكز الأمنية خصوصًا لمن يتم التحقيق معهم على الحدود ولا يجيدون اللغة. 
- - لا تحل الرموز التعبيرية محل الكلمات، بل تحل محل الإيماءات على سبيل المثال التي نستخدمها عن طريق الفم وتتكامل مع النص وتتفاعل معه.

- لم يعد الأمر يتعلق فقط بإعطاء صديق غمزة على رسالة ساخرة بعد الآن فقد ترجمت أعمال الأدب إلى رموز تعبيرية. - - تشبه الرموز التعبيرية بــ"الهيروغليفية" الّا أن المفهوم مختلف تماما فهذه الرموز التعبيرية على الأقل حتى الآن ليست لغة، بل هي شكل من أشكال التواصل في عصر الرقمنة. - - تكسر الإيموجي حاجز العزل اللغوي بين بلدان وشعوب مختلفة متباينة. - قد يؤدي تداولها بشكل يفوق اللغة الطبيعية -ـون ضوابط- بالعالم إلى عصر ما قبل اللغات المكتوبة، إلى عصر اللغات الرمزية، المسمارية والهيروغليفية والصينية واليابانية والتي يعدّها علماء اللسانيات لغات بدائية مقارنة باللغات الأبجدية التي تمثل أوج رقي العقل البشري. - ل ال يعني ازدياد ملفات GIF37 والملصقات والرموز التعبيرية المخصصة أنها سوف تحل محل اللغة وهذا لم يحدث مثنًا في عصر الفيلم الصامت. - إذا كانت جميع الرموز التعبيرية تعتمد على بروتوكول Unicode ، فإن تصميمها الجرافيكي تتم إدارته بواسطة علامات تجارية (Apple و Samsung و Gicrosoft و Google و Google) ، مما قد يؤدي إلى تفسيرات مختلفة تمامًا كما هو موضح في دراسة حديثة. - - هذه الظاهرة تقول الكثير عن مجتمعنا وأنفسنا بل تجسد بطريقتها الخاصة نقافة ويب معينة. 
- - يعيق الترجمة الرقمية حاليًا تعبيرها عن المشاعر والإيموجي استخدامها الرئيسي في التعبير عن المشاعر.

- تعتبر الرموز التعبيرية "الإيموجي" لغة غير قواعدية مفهومة من جميع الجنسيات والإثنيات وقد تكون لغة العالم المستقبلي تجمع بين لغة الرموز البشرية في البدء وتطوره العولمي بتواصله بمساحة مليارات الرسائل يوميَّا برموز تعبّر عن شعور كاتبها وأحيانًا بما قد تعجز عنه الكلمات.

لقد أصبحت الرموز التعبيرية ذات شعبية منزايدة في جميع أنحاء العالم، مما يسمح للناس من خلفيات لغوية وتقافية مختلفة بالاتصال والتفاعل مع بعضهم البعض. وتظهر معظم الرموز المتداولة حاليًا بأنها تمثل المشترك بين الثقافات المختلفة وبطرق تختصر الزمان والمكان والوقت في الكتابة والتزجمة. وعليه نوصي بدعم الجهود والتجارب لحوسبة اللغة العربية في الوطن العربي بل توحيد الجهود وتوظيف منل ظاهرة "الإيموجي" أو الاختصارات أو أي ظاهرة رقمية قادمة لتطوير اللغة من خلال إيجاد حلول للتعامل معها بنفس وتيرتها. ونوصي أيضًا بأن يكون هنالك موقع إلكتروني على الثبكة العنكبوتية موحد لمجامع اللغة العربية ومراكز حوسبة اللغة العربية من خلاله يمكن نشر كل ما يستجد من بحوث ودراسات وتجارب عبر جميع الوسائل للتفاعل المستمر وبنفس وتيرة التقنية لتعم الفائدة المرجوة.

يمكن للغات واللغة العربية تحديدًا أن تستقيد من وسائل التقنية المتتوعة والاستجابة بنفس الوتيرة لمتطلباتها حتى تتماشى مع المفهوم السائد عن اللغة بأنها كائن حي ومتطور • ولعل التقنية تمهلنا بأن نلتقط الأنفاس التي جميعنا كلما صحونا نسارع لهاتفنا المحمول لنتصفح ونتواصل مع الجميع في معظمها برموز واختصارات نفهما، مع الأمل بأن تبقى اللغة بنظامها التقلبدي وتساهم التقنية في بقائها وتطورها. بيد أن مستقبل عالم التقنية والجيل الرقمي كفيل بأن يظهر لنا لغة غير لغة "الإيموجي" بتعابير تتلاعم مع الجيل الرقمي القادم وقد يكون 
قريبًا وتبقى اللغة الطبيعية بنظامها التقليدي كائنًا حيَّا يتطور وبتتاغم مع التقنية جيلًا بعد جيل.

سيتيح للناشئة خاصة استخدام رموز بسيطة ليس مهما أن يفهموا دلالاتها العميقة للتعبير عن مشاعر بسيطة يومية تتنابهم باعتبارهم يستخدمون تطبيقات الهواتف الذكية وشبكات التواصل الاجتماعي مثال "واتس آب". وعليه من المكن تككون هذه الرموز وسيلة فعالة وكافية للتواصل بين جميع اللغات دون ترجمة أو معرفة سابقة لأي منهما بلغة الآخر وذلك في الأغراض البسيطة منل الأسئلة والردود القصبرة والتسويق ونحوه. وقد تتطور مستقبلًا للتعبير عن نصوص أعمق وقد نجد يومًا ما قصة قصيرة أو دليل / توصيف لآلة أو اختراع، إرشادات /نصائح طبية ، إلخ.. بلغة الإيموجي.

يبقى الأمر تواصلًا محدودًا ويبقى معرّضًا لوقوع سوء تفاهم بين المتخاطبين من خلال تفسير معنى الصورة التي تستخدم ولا تحمل الصور نفس الدلالات الثقافية. ومع ذلك ، على الرغم من ارتباطنا الوثيق المفاجئ بهذه الصور التوضيحية، يدعي اللغوي جون مكوورتير أنه لا يمكن للناس التواصل بشكل محض من خلال الرموز التعبيرية، لأن المتلقي يجب أن يعطى سياقًا أكثر : ما الذي يتحدث عنه المرسل وماذا حدث ومنى وما إلى ذلك. 38 وليست الرموز التعبيرية لغة جديدة، لكنها جزء أساسي من هذا السجل الجديد للغة المكتوبة غير الرسمية. تتكرر لأن مشاعرنا (الضحك ، التصفيق) غالبًا ما تتكرر أو تدوم في وقت ما نعبر عنه. تسمح الرموز التعبيرية للأشخاص العاديين بالتعبير عن المشاعر في الوقت الحقيقي

لن يتعلم أحد الرموز التعبيرية كلغة أولى. لذا على الرغم من أن الرموز التعبيرية بمكنها الإجابة عن الأسئلة وتغيير الجمل وإنشاء الشعارات، فإنها أقرب إلى اللغات العامية من أي

${ }^{38}$ https://medium.com/@BijouConcierge/the-rise-of-the-emoji-communication-in-thesmartphone-era-d94295436d34 
شيء آخر • وهي تمثل جميع حالات الحياة اليومية تقريبًا ويمكن أن تضخم من المشاعر التي يصعب أحيانًا التعبير عنها.

وأخيرًا، أن اللغة وسيلة التعامل الاجتماعي الأولى في المجتمع الإنساني، أما وسائل الاتصال الأخرى مثل الإشارات الصوتية أو الإيموجي فليست إلا محاولة بديلة للنظام اللغوي وهي تقوم أساسًا على النظام اللغوي ولذا ليس لها بدونه وجود، لكن هذه الظاهرة "الرموز التعبيرية" نقول الكثير عن مجتمعنا وتساعد وتسهل في التواصل والتخاطب بطريقة تجميع بين الرموز والصورة وقد يحصل سوء فهم لاختلاف التقافات لذا قد يكون التخاطب محدود، ويمكن للتعابير أن تساهم في حل المعوقات التي تصادف بعض اللغات في اللسانيات الحاسوبية وتكون لغة مساندة للغة الأم ومشتركة بين جميع لغات العالم للتواصل البسيط. ومن المفيد بأن تكون منل ظاهرة الرموز التعبيرية "الإيموجي" من خلال تطبيقاتها وسيلة ترجمة للتواصل البسيط وتكون أداة سهلة وسربعة للتفاهم بين مختلف اللغات. 
التوني، مصطقى زكي، علل التغيير اللغوي، حوليات كلية الآداب، جامعة الكويت الحولية13- الرسالة، 84، 1993م.

غود(اك دأنيل، (ترجمة: فايز الثهري)، مهنة المترجم، دار جامعة الملك سعود للنشر،

ANNAN Kofi, the world summit information: moving from the past into the future, Daniel Stauffacher and Wolfgang Kleinwachter, 2005

BLATTNER, G. et LOMICKA, L., "Facebook-ing and the social Generation : a new era of language learning », ALSIC, vol.15, $\mathrm{n}^{\circ} 1,2012$

CIPRIANI, Jason. "Download additional 'Stickers' for Facebook Messenger". CNET. Retrieved 2019-04-25.

DANESI Marcel, The Semiotics of Emoji: The Rise of Visual Language in the Age of the Internet, nov. 2016, Bloomsbury Publishing

ENGADGE, "Path 3 adds private messaging and stickers, much like your 5th grade binder". t. Retrieved 2019-04-25.

EVANS Vyvyan, THE EMOJI CODE, The Linguistics Behind Smiley Faces and Scaredy Cats, Picador, 2017

FORTUNE, "How one startup is turning emoji into cash". Retrieved 2019-04-25.

Joseph , Symbols: A Universal Language, Michael O'Mara Books,2013

Kaye, L. K., Malone, S. A., \& Wall, H. J., Emojis: Insights, Affordances and Possibilities for Psychological Science. Trends in Cognitive Sciences, 21 (2), (2017)

Mahwah, NJ: Erlbaum, pp. language. In Velichkovsky, B. M. and D. M. Rumbaugh (eds), Communicating Meaning. The evolution and development of language. 275-307. 
MALIKA Ivit, Trends in linguistics, Moution \& Co. N.V. ,1970

MAMIKO Nakano, "Why and how / created emoji: Interview with Shigetaka Kurita". Ignition. Translated by Mitsuyo Inaba Lee. Archived from the original on June 10, 2016. Retrieved August 16, 2015.

MARCEL Danesi, The Semiotics of Emoji: The Rise of Visual Language in the Age of the Internet, Bloomsbury Publishing, 2016

PBS Newshour, "Oxford Dictionaries 2015 Word of the Year is an Emoji", November 17, 2015. Retrieved August 23, 2017. PIERCY Pika ،S.؛ Mitani ،J. C., 'Referential gesturing in wild chimpanzees (Pan troglodytes)". Current Biology. 16: 191-192 (2006).

ROGERS Henry, Writing Systems: A Linguistic Approach. Oxford: Blackwell, 2005 .

RUSSELL, Jon, "Stickers: From Japanese Craze to Global Messaging Phenomenon" 2013.

RUSSELL, Jon, "Kiks Add Stickers and Third-Party Games". Retrieved 2019$04-25$.

TechCrunch, "Facebook Brings Its Mobile Messaging Stickers to The Web as Their Designer Exits". Retrieved 2019-04-25.

TechCrunch."Global Mobile Android/iOS Messaging App Map Dominated by WhatsApp - But BBM Bags A Foothold". Retrieved 2019-04-25.

www.sites.utexas.edu, "The Evolution of Writing", ,25-1-2014 ،Retrieved 14-52018. Edited.

www.blogs.ntu.edu.sg, "Origins and Evolution of Writing Systems" ,22-3-2017, Retrieved 14-5-2018. Edited. 